\title{
New leaf- and litter-dwelling species of the genus Pholcus from Southeast Asia (Araneae, Pholcidae)
}

\author{
Bernhard A. HUBER ${ }^{1, *}$, Joseph K.H. KOH ${ }^{2}$, Amir-Ridhwan M. GHAZALI ${ }^{3}$, Kamil A. \\ BRAIMA $^{4}$, Olga M. NUÑEZA ${ }^{5}$, Charles LEH MOI UNG ${ }^{6}$, Booppa PETCHARAD ${ }^{7}$ \\ 1,* Alexander Koenig Research Museum of Zoology, Adenauerallee 160, 53113 Bonn, Germany. \\ ${ }^{2}$ National Biodiversity Centre, National Parks Board, 1B Cluny Road, Singapore 259598. \\ ${ }^{3}$ Centre for Research and Consultancy, Unitar International University, Malaysia. \\ ${ }^{4}$ University of Malaya, Kuala Lumpur, Malaysia. \\ ${ }^{5}$ Department of Biological Sciences, Mindanao State University - Iligan Institute of Technology, \\ Tibanga, Iligan City 9200, Philippines. \\ ${ }^{6}$ Sarawak Museum, Jalan Tun Abang Haji Openg, 93566 Kuching, Sarawak, Malaysia. \\ ${ }^{7}$ Department of Biology, Faculty of Science, Prince of Songkla University, \\ Hat Yai, Songkhla 90112, Thailand. \\ * Corresponding author: b.huber@zfmk.de \\ ${ }^{2}$ Email: josephkhkoh@gmail.com \\ ${ }^{3}$ Email: amir.ridhwan@gmail.com \\ ${ }^{4}$ Email: kamilalibraima@gmail.com \\ ${ }^{5}$ Email: olgamnuneza@yahoo.com \\ ${ }^{6}$ Email: charllmu@sarawak.gov.my \\ ${ }^{7}$ Email: zigzagargiope@yahoo.com \\ ${ }^{1}$ urn:lsid:zoobank.org:author:33607F65-19BF-4DC9-94FD-4BB88CED455F \\ ${ }^{2}$ urn:Isid:zoobank.org:author:DA9CA194-2A90-41BD-8109-D8E536F23C0C \\ ${ }^{3}$ urn:lsid:zoobank.org:author:EA038837-AA7B-49F0-8012-2B23C36F1605 \\ ${ }^{4}$ urn:Isid:zoobank.org:author:A9BD39AB-FD69-4740-A1DA-845D4F3B232B \\ ${ }^{5}$ urn:Isid:zoobank.org:author:6D14FCCC-F148-4293-9F23-0EB5A4119305 \\ ${ }^{6}$ urn:Isid:zoobank.org:author:BF48A807-815E-41E4-BCC6-F3A3FAEDBC9E \\ ${ }^{7}$ urn:1sid:zoobank.org:author:E1480A4E-3FA8-441C-A803-515B8AE7860D
}

\begin{abstract}
We describe eight new species of the genus Pholcus, and document their microhabitats. Four species are assigned to the previously described Pholcus ethagala group: P. tanahrata Huber sp. nov., P. uludong Huber sp. nov., and P. bukittimah Huber sp. nov. from the Malay Peninsula, and P. barisan Huber sp. nov. from Sumatra. These species are all litter-dwellers that build domed sheet webs on the undersides of large dead leaves on the ground. The other four species are assigned to newly created species groups: the P. tambunan group with two species from northern Borneo: P. tambunan Huber sp. nov. and $P$. bario Huber sp. nov.; and the $P$. domingo group with two species from the Philippines, Mindanao: P. domingo Huber sp. nov. and $P$. matutum Huber sp. nov. These latter four species are leafdwellers that build barely visible silk platforms tightly attached to the undersides of live leaves. The
\end{abstract}


main rationale for this paper is to provide part of the taxonomic and natural history background for upcoming phylogenetic and evolutionary (microhabitat shifts) analyses.

Keywords. Pholcus, Southeast Asia, taxonomy, microhabitat, ultrastructure.

Huber B.A., Koh J.K.H., Ghazali A.-R.M., Braima K.A., Nuñeza O.M., Leh Moi Ung C. \& Petcharad B. 2016. New leaf- and litter-dwelling species of the genus Pholcus from Southeast Asia (Araneae, Pholcidae). European Journal of Taxonomy 200: 1-45. http://dx.doi.org/10.5852/ejt.2016.200

\section{Introduction}

Pholcidae occupy a wide range of microhabitats, particularly in tropical forests. Some prefer leaf litter, some live in larger sheltered spaces among rocks and logs and in caves, some build their webs freely among vegetation, and some are found on the undersides of live leaves up to several meters above ground. While some genera are homogeneous in this respect (e.g., all Ninetinae seem to be ground-dwellers; all Calapnita Simon, 1892 seem to be leaf-dwellers), others include representatives from various different microhabitats (e.g., Belisana Thorell, 1898; Mesabolivar González-Sponga, 1998; Metagonia Simon, 1893; Modisimus Simon, 1893; Smeringopus Simon 1890; see Huber 2005, 2012, 2015 and Huber et al. 2005, 2010). This implies that evolutionary microhabitat shifts have occurred, both among and within genera. Several such shifts have recently been documented in some detail (e.g., Dimitrov et al. 2013; Huber et al. 2015), but our general understanding of the patterns is still rudimentary because it requires good data about both microhabitat and phylogeny, and at least one of them is often missing or incomplete.

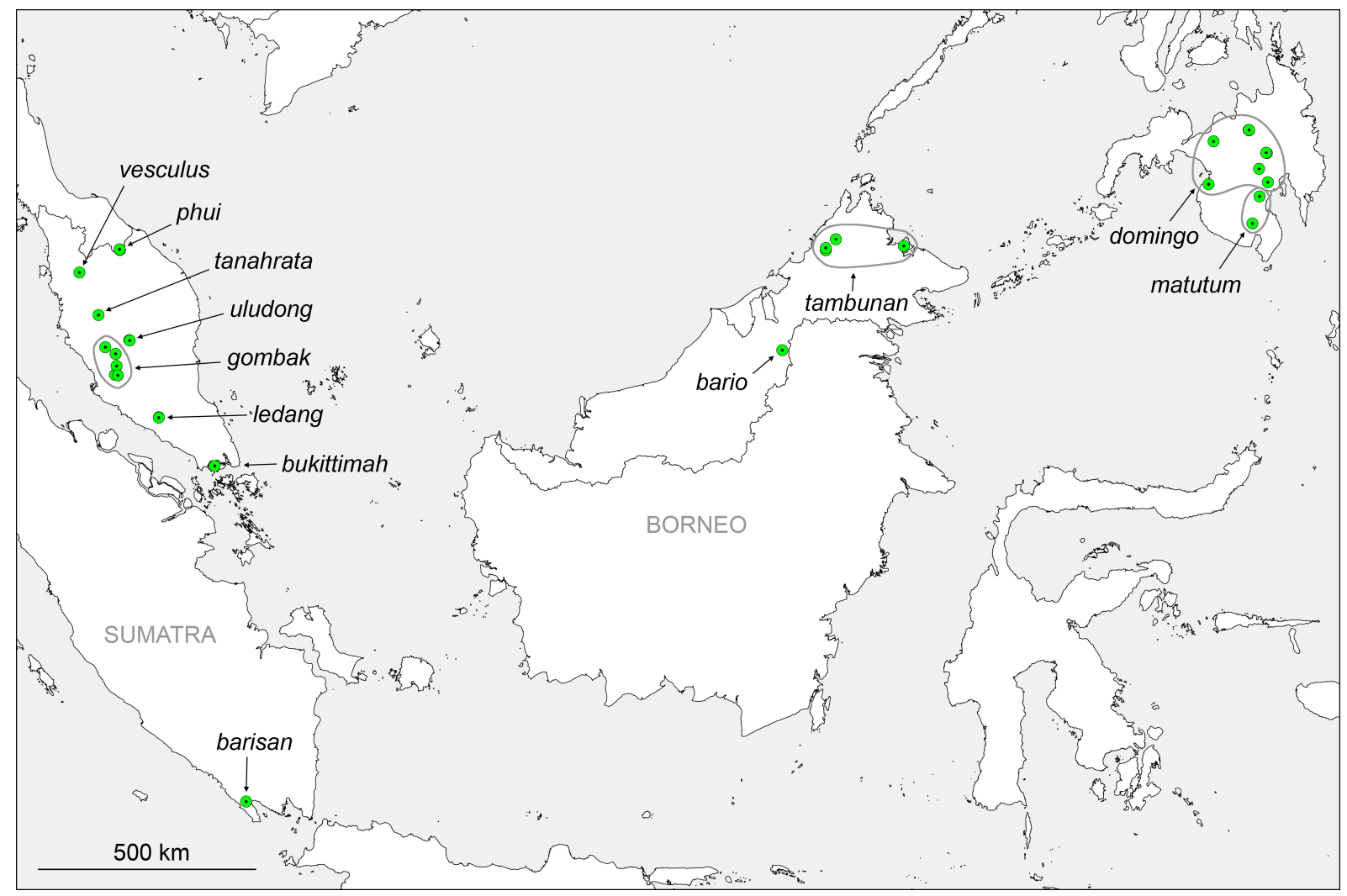

Fig. 1. Known distributions of the Pholcus ethagala group (Malay Peninsula and Sumatra; Sri Lankan species not shown), of the P. tambunan group (Borneo) and of the P. domingo group (Philippines). 
Of particular interest in this respect is the genus Pholcus Walckenaer, 1805. Almost every microhabitat accessible to Pholcidae in general is occupied by specific representatives of this large genus. Most species groups in Pholcus that appear well supported are homogeneous with respect to their microhabitat, but relationships among groups do not seem to correlate with microhabitat preferences and in some cases even closely related species occupy different microhabitats (Dimitrov et al. 2013; Huber \& Dimitrov 2014). This suggests multiple convergent shifts of microhabitat in Pholcus alone. Preliminary phylogenetic data suggest that the story may be even more complicated. Several genera currently considered close to Pholcus, such as Calapnita Simon, 1892; Leptopholcus Simon, 1893; Micropholcus Deeleman-Reinhold \& Prinsen, 1987; Micromerys Bradley, 1877; Panjange Deeleman-Reinhold \& Deeleman, 1983; etc. (the Pholcus group of genera in Huber 2011) may actually be nested within a paraphyletic Pholcus (Huber 2011; A. Valdez-Mondragón, B.A. Huber \& D. Dimitrov, unpublished data). If this proves to be correct, then these mostly leaf-dwelling taxa may represent numerous additional microhabitat shifts within this large taxonomic group (currently comprising some 400 described species).

The present paper focuses on Pholcus in Southeast Asia (Fig. 1) and is one of several recent contributions providing the taxonomic and natural history background for an upcoming analysis of microhabitat shifts in Pholcidae. Of particular interest in this respect is the Pholcus ethagala group because previous cladistic analyses (Huber 2011) have suggested a close relationship between this group (whose Southeast Asian representatives turn out to be litter-dwelling; e.g., Figs 2-9) and the leaf-dwelling genus Panjange. The other two species groups treated below are also 'untypical' Pholcus (e.g., they both lack an uncus on the male genital bulb) and might previously have been considered to represent new genera, but preliminary analyses of molecular data (A. Valdez-Mondragón, B.A. Huber \& D. Dimitrov, unpublished data) strongly support their inclusion in Pholcus, i.e., a close relationship with more 'typical' Pholcus. We deliberately do not dwell on phylogenetic aspects in this paper as all species treated below will be included in the comprehensive molecular phylogeny to be published in 2017.

\section{Material and methods}

Most of the material studied herein was collected during recent expeditions to the Philippines (Feb.Mar. 2014), northern Borneo (Jul.-Aug. 2014), and the Malay Peninsula (Feb.-Mar. 2015). This material is currently deposited at the following institutions: Mindanao State University - Iligan Institute of Technology, Iligan (MSU-IIT), Philippines; Museum of Zoology, University of Malaya, Kuala Lumpur (MZUM), Malaysia; Princess Maha Chakri Sirinthorn Natural History Museum, Prince of Songkla University, Hat Yai (PSUZC), Thailand; Sarawak Museum, Kuching (SMK), Malaysia; and Zoologisches Forschungsmuseum Alexander Koenig, Bonn (ZFMK), Germany. Further material came from the American Museum of Natural History, New York (AMNH); and the Netherlands Centre for Biodiversity Naturalis, Leiden (RMNH).

Methods and terminology used are as in Huber (2011). Measurements are in mm unless otherwise specified. Eye measurements are approx. $\pm 5 \mu \mathrm{m}$. Epigyna were cleared in warm $\mathrm{NaOH}$ solution and stained with chlorazol black. For SEM photos, specimens were dried in hexamethyldisilazane (HMDS) (Brown 1993), and photographed with a Hitachi S-2460 scanning electron microscope. SEM data are presented within the descriptions but are not based on the holotype specimens described. Locality coordinates are in round brackets when copied from labels and original publications or when received directly from collectors, in square brackets when originating from some other source (such as online gazetteers, Google Earth, etc.). The distribution map was generated with ArcMap 10.0.

\section{Abbreviations}

a $\quad=$ appendix

$\mathrm{ALE}=$ anterior lateral eye $(\mathrm{s})$ 


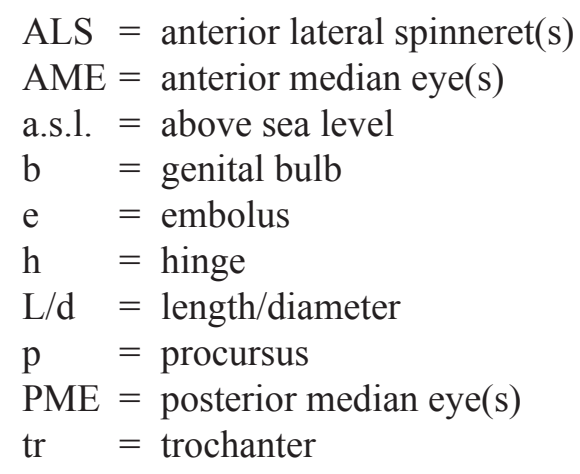

\title{
Results
}

Taxonomy

\author{
Class Arachnida Cuvier, 1812 \\ Order Araneae Clerck, 1757 \\ Family Pholcidae C.L. Koch, 1851
}

Pholcus Walckenaer, 1805

Pholcus Walckenaer 1805: 80. Type species by (assumed) monotypy: Aranea phalangioides Fuesslin, 1775.

Pholcus - Huber 2011: 124-126.

Pholcus ethagala species group

\section{Diagnosis}

This group (proposed in Huber 2011) includes medium-sized, long-legged spiders (body length $~ 3.0$ 4.5, male leg 1 length: 30-40); distinguished from similar species groups in Pholcus (P. minang and P. kerinci groups proposed in Huber 2011, and P. buatong group proposed in Huber et al. 2016) by combination of following characters: elongate abdomen slightly angular or pointed dorso-posteriorly (Figs 5, 32); six eyes (in contrast to P. kerinci group; only the dubious P. vesculus Simon, 1901 with eight eyes); male eye triads on stalks (Figs 39, 48, 77-80; in contrast to $P$. kerinci group); male chelicerae with distinct proximal apophyses in frontal position (Figs 12, 17, 69, 74; in contrast to P. kerinci and $P$. buatong groups), without distal apophyses (in contrast to $P$. minang group); male palpal trochanter with short retrolateral apophysis and longer to very long ventral apophyses (Figs 11, 16, 68, 73; short only in P. gombak Huber, 2011); male palpal patella dorsally not bulging (in contrast to P. buatong group); palpal tarsus with dorsal elongation (Figs 11, 68; except P. phui Huber, 2011 and P. barisan Huber sp. nov.), bulb with large and often complex appendix and weakly sclerotized embolus, without uncus; procursus highly complex, with dorsal (sometimes rather prolateral) process and hinged distal element; epigynum weakly sclerotized, with small 'knob' (Figs 13, 18, 70, 75; in contrast to $P$. buatong group).

\section{Description - amendments}

The original description (Huber 2011) is still largely valid. The following can be added: clypeus usually unmodified but with pair of small processes in P. barisan Huber sp. nov. (Fig. 80); male palpal femur ventrally very variable, from barely modified (P. barisan Huber sp. nov.; Fig. 73) to distinct processes (P. ethagala Huber, 2011; P. phui Huber, 2011; P. ledang Huber, 2011; P. gombak Huber, 2011). Genital bulb without uncus but in some species with small sclerite that originates from proximal bulbal sclerite (arrows in Figs 15, 25, 67) and might be homologous to the uncus present in most other Pholcus groups. 
Tibia 1 in males 6-10; tibia $1 \mathrm{~L} / \mathrm{d} \sim 80-105$; tibia $2 /$ tibia 4 usually about $1.05-1.15$, in $P$. uludong Huber sp. nov. 1.00. Male gonopore usually with four epiandrous spigots (Figs 46, 57; the three spigots in the specimen figured in Huber 2011: fig. 803 is probably an individual exception). Tarsus 4 comb-hairs of the simplified Pholcus-type (cf. Huber \& Fleckenstein 2008), with four lateral tines (Figs 28, 50).

\section{Composition}

The $P$. ethagala group now includes ten species: two species on Sri Lanka (P. ethagala; $P$. maturata Huber, 2011), seven species on the Malay Peninsula (P. phui; P. vesculus; P. tanahrata Huber sp. nov.; $P$. uludong Huber sp. nov; P. gombak; P. ledang; P. bukittimah Huber sp. nov.) and one species on Sumatra (P. barisan Huber sp. nov.). The poorly known $P$. vesculus is assigned tentatively and probably misplaced (see Huber 2011). Originally, P. schwendingeri Huber, 2011 was also assigned tentatively to this group; it has recently been transferred to the newly created $P$. buatong group (Huber et al. 2016).

\section{Natural history}

The seven species newly observed in the field (Malay Peninsula and Sumatra) were mostly found on the undersides of large dead leaves on the ground. This is in contrast to the two Sri Lankan species that supposedly live on live leaves (at least P. ethagala; Huber 2011). Very few specimens of the newly observed species were also found under logs (P. ledang) and in bamboo sheaths and under rocks (P. gombak). The availability of suitable large leaves on the forest floor strongly influenced spider abundance. Webs consisted of small domed sheets closely attached to the leaf surface. When disturbed, the spiders barely reacted; they vibrated only for a short time at low amplitude or were not seen to vibrate at all. Two egg-sacs (of two species) were parasitized by Idris Foerster, 1856 (Scelionidae, Baeini) wasps (Figs 33-35, 62). For further information see individual descriptions below.

\section{Distribution}

The P. ethagala group is known from Sri Lanka (see Huber 2011; not treated herein and not shown in Fig. 1) and from Southeast Asia (Malay Peninsula, Sumatra; Fig. 1).

Pholcus phui Huber, 2011

Figs 2-3

Pholcus phui Huber, 2011: 178-180, figs 749-752, 779-780, 809-813 (ð̊ㅇ).

\section{Diagnosis}

Easily distinguished from most similar known relatives (other species of the P. ethagala group on the Malay Peninsula) by morphology of male palps (figs 809-810 in Huber 2011; procursus with two distinctive dorsal processes and curved distal process; large appendix distally with whitish element and with sclerotized element set with small scales), and by details of female internal genitalia (figs 812-813 in Huber 2011; distinctive pair of anterior lateral structures; roundish pore plates close together).

\section{New material examined}

THAILAND: $2 \hat{\jmath} \widehat{\partial}, 1$, 1 juv., ZFMK (Ar 15691), and $1 \hat{\partial}, 1$ , PSUZC, Narathiwat Province, Hala Bala Wildlife Sanctuary, 'site 3' $\left(5.808^{\circ} \mathrm{N}, 101.823^{\circ} \mathrm{E}\right), 220 \mathrm{~m}$ a.s.l., forest near road, leaf litter, 2 Mar. 2015 (B.A. Huber, B. Petcharad); 4 우, 3 juvs, in absolute ethanol, ZFMK (Mal 309), same data.

\section{Description - amendments}

Tibia 1 in three newly collected males: 9.3, 9.6, 9.7; tibia 2/tibia 4 length: 1.08. 


\section{Natural history}

All specimens were collected within a small swampy area in the forest that was characterized by numerous large dead leaves on the ground. Almost each of the largest leaves had an adult Pholcus phui on its lower surface, while the more numerous smaller leaves were mostly either unoccupied or occupied by juveniles. No further specimens were found during three days of collecting in various parts of the forest.
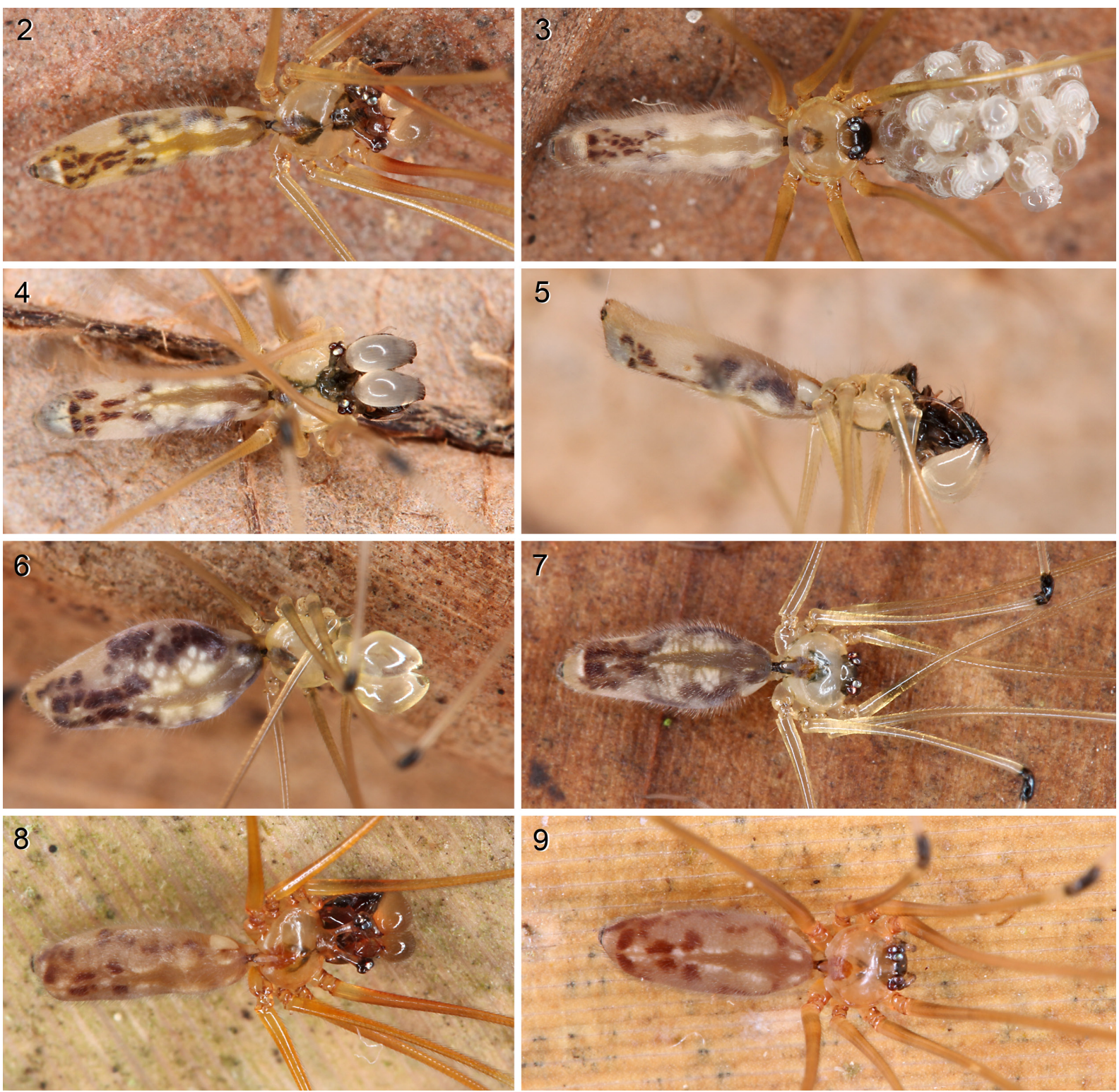

Figs 2-9. Live specimens. 2-3. Pholcus phui Huber, 2011, Hala Bala, $\delta^{\Uparrow}$ and $q$ with egg-sac. 4-7. P. tanahrata Huber sp. nov., Cameron Highlands, $\partial$, penultimate ${ }^{\lambda}$, and + . 8-9. P. uludong Huber sp. nov., Ulu Dong, $\widehat{\jmath}$ and $q$. 


\section{Pholcus tanahrata Huber sp. nov. urn:1sid:zoobank.org:act:F930688A-BB3D-4FEB-9FCE-3AB42FDF581D}

Figs 4-7, 10-14, 77, 81-83

\section{Diagnosis}

Easily distinguished from most similar known relatives (other species of the $P$. ethagala group on the Malay Peninsula) by morphology of male palps (Figs 10-11; procursus with two distinctive dorsal processes, each with bifid tip), and by details of female internal genitalia (Figs 13, 14; pair of anteriorly converging lateral sclerites visible through cuticle; elongate parallel pore plates).

\section{Etymology}

The species is named for Tanah Rata, the town close to the type locality; noun in apposition.

\section{Material examined}

\section{Holotype}

MALAYSIA: ${ }^{\lambda}$, ZFMK (Ar 15692), Pahang, Cameron Highlands $\left(4.460^{\circ} \mathrm{N}, 101.392^{\circ} \mathrm{E}\right), 1200 \mathrm{~m}$ a.s.1., forest along 'trail 9', leaf litter, 25 Feb. 2015 (B.A. Huber); adult 26 Feb. 2015; fixed 28 Feb. 2015.

\section{Other material}

MALAYSIA: 1 + , ZFMK, together with holotype; 1 त, ZFMK (Ar 15693), same data, adult 1 Mar. 2015; died while molting; fixed 2 Mar. 2015; 4 juvs, in absolute ethanol, ZFMK (Mal 283), same data as holotype.

\section{Description}

\section{Male (holotype)}

MeAsurements. Total body length 3.9, carapace width 1.05. Leg 1: $38.5(8.9+0.5+9.0+18.0+2.1)$, tibia 2: 5.4, tibia 3: 3.3, tibia 4: 4.8; tibia $1 \mathrm{~L} / \mathrm{d}$ : 103. Distance PME-PME $570 \mu \mathrm{m}$, diameter PME $125 \mu \mathrm{m}$, distance PME-ALE $\sim 35 \mu \mathrm{m}$; AME absent.

CoLOR. Carapace ochre-yellow with light brown triangular mark posteriorly, ocular area, eye stalks and clypeus light brown, some irregular back pigment in AME area; sternum whitish, labium brown; legs ochre-yellow with darker brown patellae and tibia-metatarsus joints; abdomen ochre-gray with some dark marks dorsally and laterally, monochromous ventrally.

Body. Habitus as in Figs 4-5; ocular area raised, each triad on long stalk (Fig. 77); carapace without median furrow; clypeus unmodified; sternum wider than long $(0.76 / 0.52)$, unmodified.

Chelicerae. As in Fig. 12, with single pair of frontal proximal apophyses directed towards median; without distal modification; without stridulatory ridges.

PaLPS. As in Figs 10-11; coxa unmodified; trochanter with very long curved retrolatero-ventral apophysis and small weakly sclerotized retrolateral process; femur with indistinct retrolatero-dorsal hump proximally and ventral hump more distally; tarsus with large rounded elongation; procursus complex, proximal part with large ventral 'knee' and complex dorsal and prolateral processes; hinged distal part with distinctive flat dorsal process and whitish areas retrolaterally and prolaterally, transparent processes prolaterally; bulb with very large appendix, long slender embolus, with small uncus-like process partly sclerotized as continuation of proximal bulbal sclerite (hidden by bulb in Fig. 10). 
Legs. Without spines and curved hairs; few vertical hairs; retrolateral trichobothrium on tibia 1 at $3 \%$; prolateral trichobothrium absent on tibia 1, present on other tibiae; tarsus 1 with apparently $>30$ pseudosegments, very indistinct except distally.

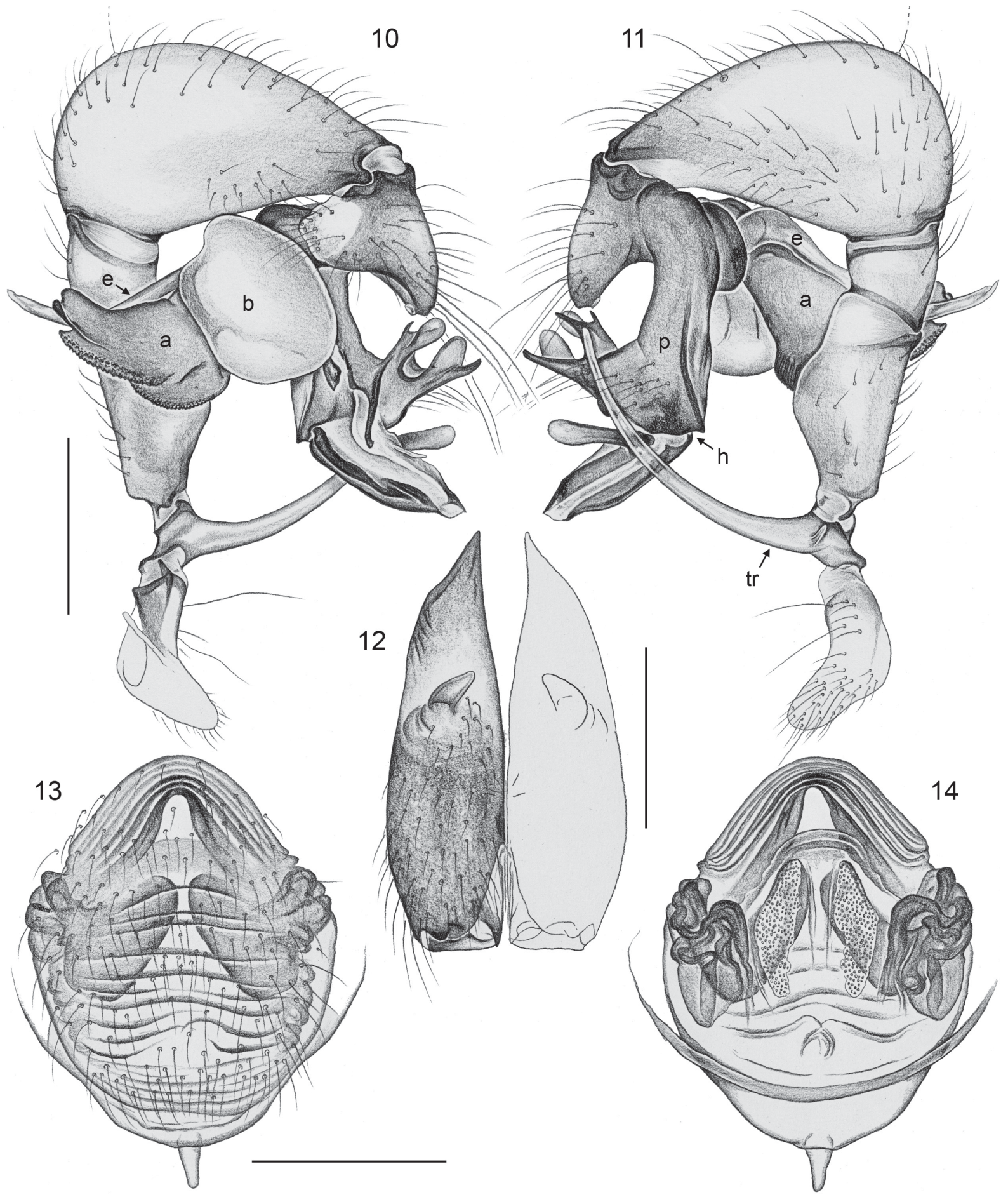

Figs 10-14. Pholcus tanahrata Huber sp. nov. (ZFMK, Ar 15692). 10-11. Left male palp, prolateral and retrolateral views. 12. Male chelicerae, frontal view. 13-14. Cleared female genitalia, ventral and dorsal views. Scale bars: $10-11,13-14=0.5 \mathrm{~mm} ; 12=0.3 \mathrm{~mm}$. 
Male (variation)

Tibia 1 in other male: 9.7; this second male died while molting and is thus very pale; genitalia identical to holotype.

\section{Female}

In general similar to male but eye triads not on stalks and much closer together than in male (PME-PME distance: $230 \mu \mathrm{m}$ ); clypeus and ocular area frontally dark brown. Tibia 1 in 1 female: 6.7. Epigynum weakly sclerotized (Fig. 81), 'knob' at posterior rim also weakly sclerotized; distinctive internal sclerites converging anteriorly (Fig. 13); internal genitalia as in Figs 14, 82, 83.

\section{Natural history}

All specimens were found under large dead leaves on the ground. Such leaves were very rare at the type locality, which explains the low number of specimens despite several hours of intensive search.

\section{Distribution}

Known from type locality in Malaysia only (Fig. 1).

$$
\begin{aligned}
& \text { Pholcus uludong Huber sp. nov. } \\
& \text { urn:1sid:zoobank.org:act:B379B03A-5BA0-4FEF-816D-DE9C3E6068A9 }
\end{aligned}
$$

Figs $8-9,15-31,78,84-86$

\section{Diagnosis}

Easily distinguished from most similar known relatives (other species of the $P$. ethagala group on the Malay Peninsula) by morphology of male palps (Figs 15-16; procursus with large flat dorsal process; large appendix distally with two rounded sclerotized elements set with small scales; relatively straight trochanter apophysis similar only to $P$. phui), by large anterior square-shaped structure in female internal genitalia, and by elongate anteriorly converging pore plates (Figs 18-19).

\section{Etymology}

The species name is derived from the type locality; noun in apposition.

\section{Material examined}

\section{Holotype}

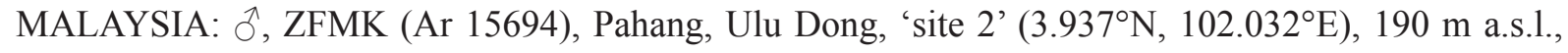
forest near river, leaf litter, 21 Feb. 2015 (B.A. Huber, A.R.M. Ghazali, K.A. Braima).

\section{Other material}

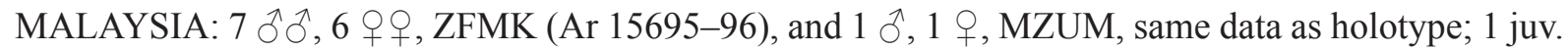

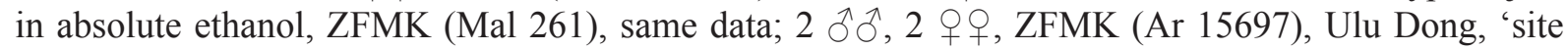
$1^{\prime}\left(3.942^{\circ} \mathrm{N}, 102.027^{\circ} \mathrm{E}\right), 190 \mathrm{~m}$ a.s.1., forest near river, leaf litter, 20 Feb. 2015 (B.A. Huber, A.R.M. Ghazali, K.A. Braima); 2 우, 1 juv., in absolute ethanol, ZFMK (Mal 250).

\section{Description}

Male (holotype)

Measurements. Total body length 3.7, carapace width 1.05. Leg 1: $32.4(7.6+0.4+7.7+14.8+1.9)$, tibia 2: 4.3, tibia 3: 2.9, tibia 4: 4.3; tibia $1 \mathrm{~L} / \mathrm{d}: 88$. Distance PME-PME $520 \mu \mathrm{m}$, diameter PME $115 \mu \mathrm{m}$, distance PME-ALE $\sim 35 \mu \mathrm{m}$; AME absent. 
COLOR. Carapace ochre-yellow with light brown median V-mark, clypeus light brown, ocular area not darkened; sternum ochre-yellow with slightly darker margins; legs ochre-yellow with darker brown patellae and tibia-metatarsus joints; abdomen ochre-gray with small black marks dorsally and laterally.

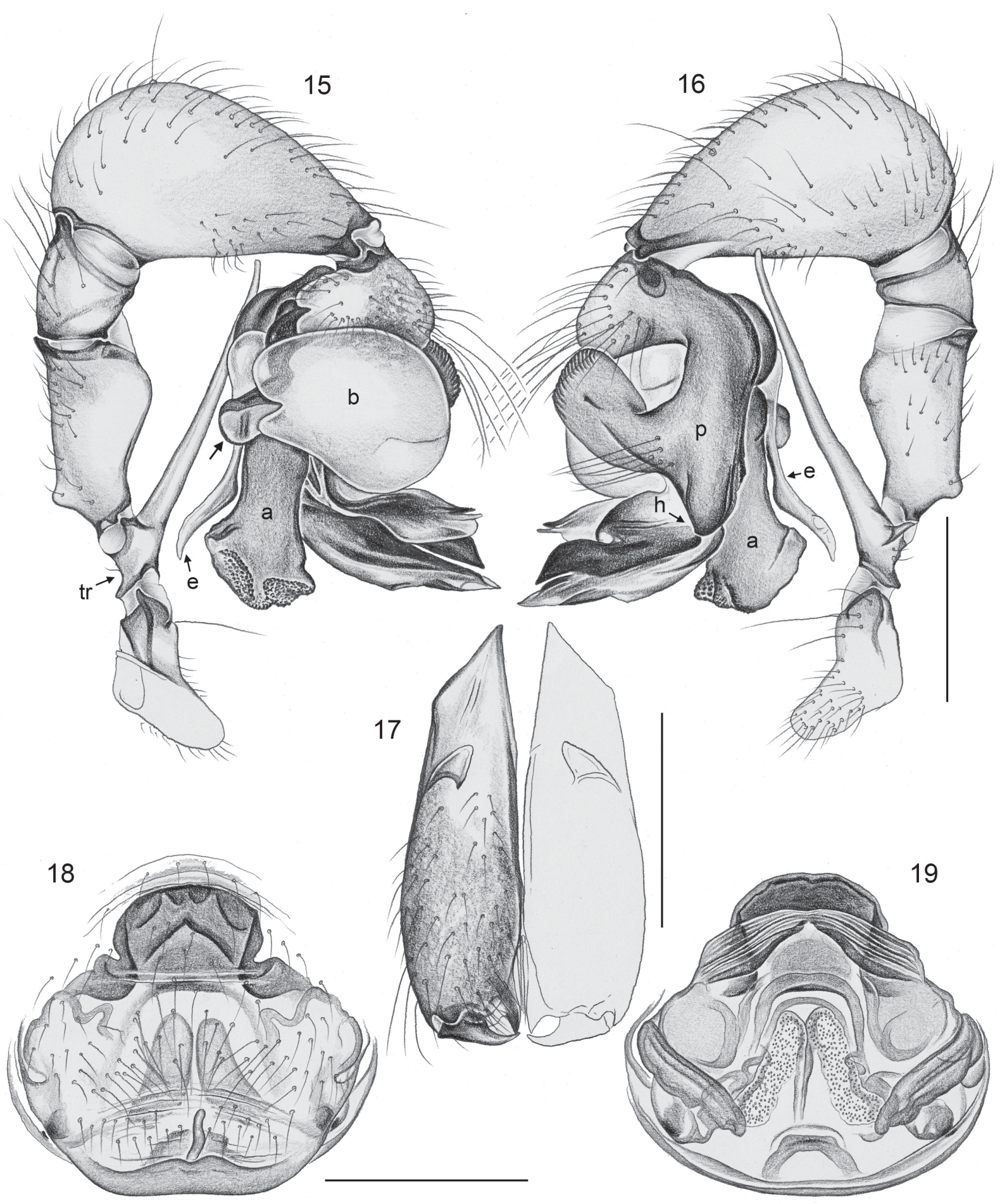

Figs 15-19. Pholcus uludong Huber sp. nov. (ZFMK, Ar 15695-96). 15-16. Left male palp, prolateral and retrolateral views; arrow points at uncus-like process of proximal bulbal sclerite. 17. Male chelicerae, frontal view. 18-19. Cleared female genitalia, ventral and dorsal views. Scale bars: 15-16, $18-19=0.5 \mathrm{~mm} ; 17=0.3 \mathrm{~mm}$. 
Body. Habitus as in Fig. 8; ocular area raised and each triad on long stalk (Figs 20, 78); carapace without median furrow; clypeus unmodified; sternum wider than long (0.70/0.54), unmodified. ALS with one widened, one pointed, and six smaller cylindrically-shaped spigots (Fig. 29).

Chelicerae. As in Fig. 17, with single pair of frontal proximal apophyses; without distal modification; without stridulatory ridges.

PaLPs. As in Figs 15-16, 22; coxa unmodified; trochanter with very long straight retrolatero-ventral apophysis and small retrolateral apophysis; femur with dorsal and ventral rounded processes; procursus
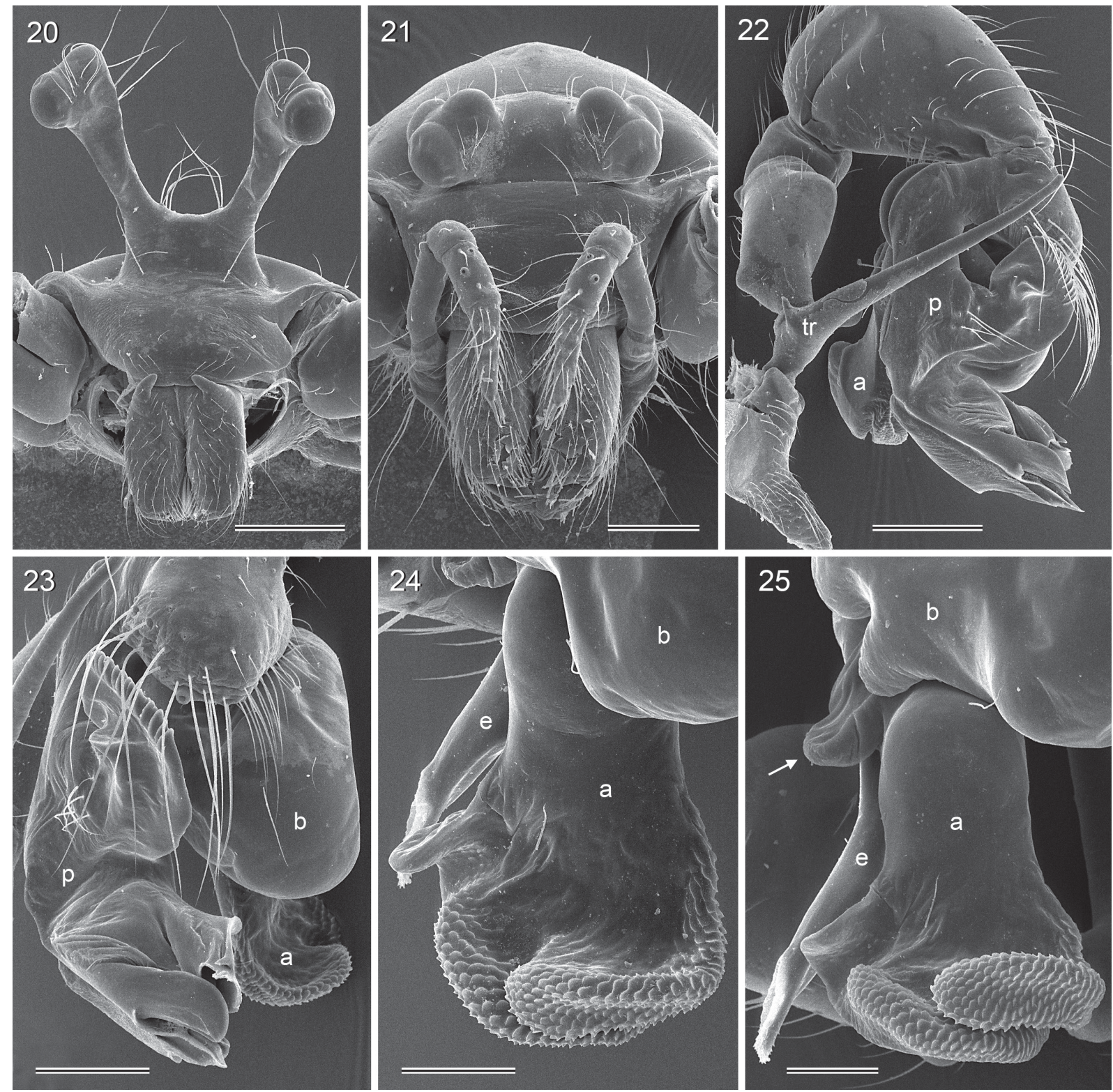

Figs 20-25. Pholcus uludong Huber sp. nov., SEM micrographs (ZFMK, Ar 15695-96). 20-21. Male and female prosomata, frontal views. 22. Right male palp, retrolateral view. 23. Right procursus and bulb, dorsal view. 24-25. Left bulb with appendix and embolus, prolateral and prolatero-dorsal views; arrow points at uncus-like process of proximal bulbal sclerite. Scale bars: 20, $22=300 \mu \mathrm{m} ; 21,23=200$ $\mu \mathrm{m} ; 24-25=100 \mu \mathrm{m}$. 
very complex, proximal part with large dorsal flat process with serrated rim (Figs 23, 27); with hinged distal elements; bulb with large appendix (Figs 24-25), long slender embolus, and two rounded processes at base of appendix, one partly sclerotized as continuation of proximal bulbal sclerite.

LEGS. Without spines and curved hairs; few vertical hairs; retrolateral trichobothrium on tibia 1 at 3\%; prolateral trichobothrium absent on tibia 1, present on other tibiae; tarsus 1 with $\sim 30$ pseudosegments, indistinct and apparently irregular. Tarsus 4 comb-hairs as in Fig. 28.
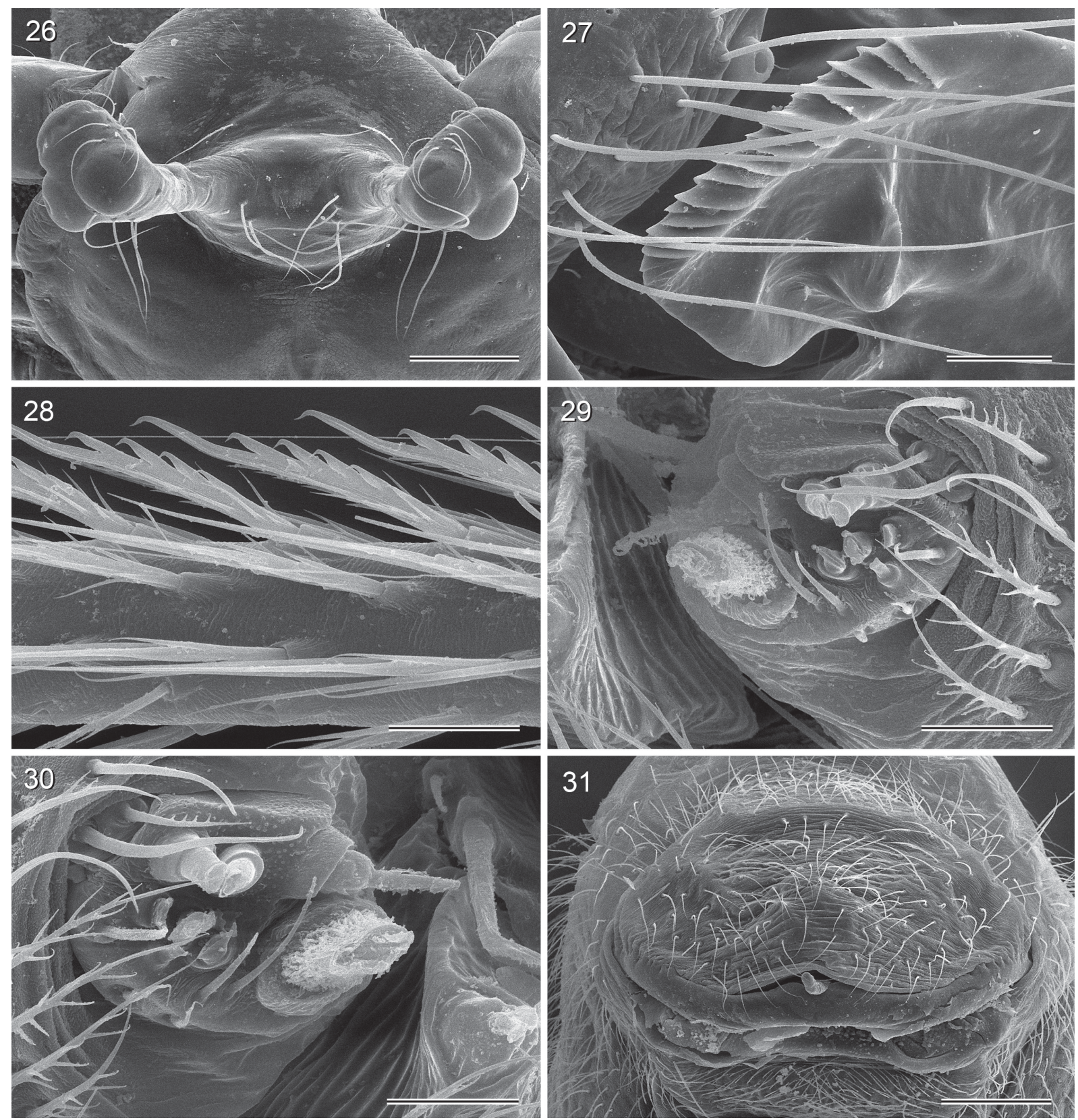

Figs 26-31. Pholcus uludong Huber sp. nov., SEM micrographs (ZFMK, Ar 15695-96). 26. Male ocular area, dorsal view. 27. Dorsal process of right procursus. 28. Comb-hairs on male tarsus 4. 29-30. Male and female ALS. 31. Epigynum, ventral view. Scale bars: $26,31=200 \mu \mathrm{m} ; 27=60 \mu \mathrm{m} ; 28-30=20 \mu \mathrm{m}$. 
Male (variation)

Tibia 1 in 9 other males: 6.3-7.8 (mean 7.1).

\section{Female}

In general similar to male (Fig. 9) but eye triads not on stalks and much closer together than in male (Fig. 21; PME-PME distance: $195 \mu \mathrm{m}$ ); clypeus darker brown. Tibia 1 in 9 females: 5.3-5.7 (mean 5.5). Epigynum weakly sclerotized and strongly bulging plate (Fig. 84), only posterior rim slightly more sclerotized, with small elongate 'knob' (Figs 18, 31); internal genitalia with large anterior square-shaped sclerite visible through cuticle and pair of weakly sclerotized folds more laterally (Figs 19, 85-86). ALS as in male (Fig. 30).

\section{Natural history}

All specimens were found under large dead leaves on the ground. They barely reacted to disturbance.

\section{Distribution}

Known from type locality in Malaysia only (Fig. 1).

Pholcus gombak Huber, 2011

Figs 32-35, 39-47

Pholcus gombak Huber, 2011: 180-183, figs 757-760, 784-785, 819-822 (ð̊ㅇ).

\section{Diagnosis}

Easily distinguished from most similar known relatives (other species of the $P$. ethagala group on the Malay Peninsula) by morphology of male palps (figs 819-820 in Huber 2011; short ventral trochanter apophysis; procursus proximal part with prolateral rather than dorsal process, with large retrolateroventral whitish area, with distinctive complex tip), and by details of female internal genitalia (figs 821822 in Huber 2011; pore plates widening anteriorly).

\section{New material examined}

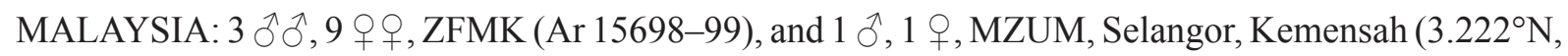
$\left.101.793^{\circ} \mathrm{E}\right), 230 \mathrm{~m}$ a.s.l., forest along stream, leaf litter, 19 Feb. 2015 (B.A. Huber, A.R.M. Ghazali,

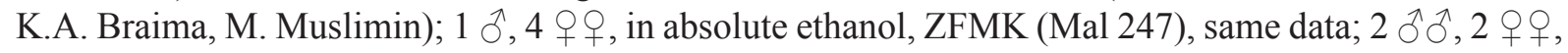
ZFMK (Ar 15700), Selangor, Fraser's Hill $\left(3.660^{\circ} \mathrm{N}, 101.743^{\circ} \mathrm{E}\right), 730 \mathrm{~m}$ a.s.l., forest near road, leaf litter, 21 Feb. 2015 (B.A. Huber, A.R.M. Ghazali, K.A. Braima); 1 q, 3 juvs, in absolute ethanol, ZFMK

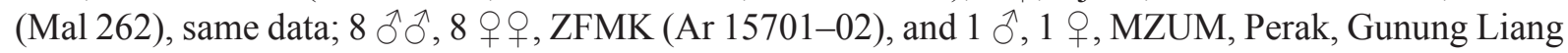
$\left(3.795^{\circ} \mathrm{N}, 101.533^{\circ} \mathrm{E}\right), 250 \mathrm{~m}$ a.s.l., forest along river, leaf litter, 22 Feb. 2015 (B.A. Huber, A.R.M. Ghazali, K.A. Braima); 3 우, 2 juvs, in absolute ethanol, ZFMK (Mal 267), same data; 1 , , in absolute ethanol, ZFMK (Mal 305), same data, with parasitized egg-sac, wasps eclosed on 1 Mar. 2015.

\section{Description - amendments}

Whitish area on procursus set with many small cuticular pointed processes (Fig. 45), procursus proximal part with prolateral rather than dorsal process (asterisk in Fig. 41). Appendix with prolateral groove and dense cover of small scales (Figs 42-43). Male gonopore with four epiandrous spigots (Fig. 46). ALS with one large widened, one pointed, and six smaller cylindrically-shaped spigots (Fig. 44). Tibia 1 in 13 males: 6.8-8.6 (mean 7.8); in 17 females: 5.4-6.6 (mean 6.1). 


\section{Natural history}

Most specimens were found under large dead leaves on the ground. At Kemensah, they also lived in bamboo sheaths and in sheltered spaces under rocks. The egg-sac of one female from Gunung Liang was parasitized by Idris wasps (Figs 33-35).
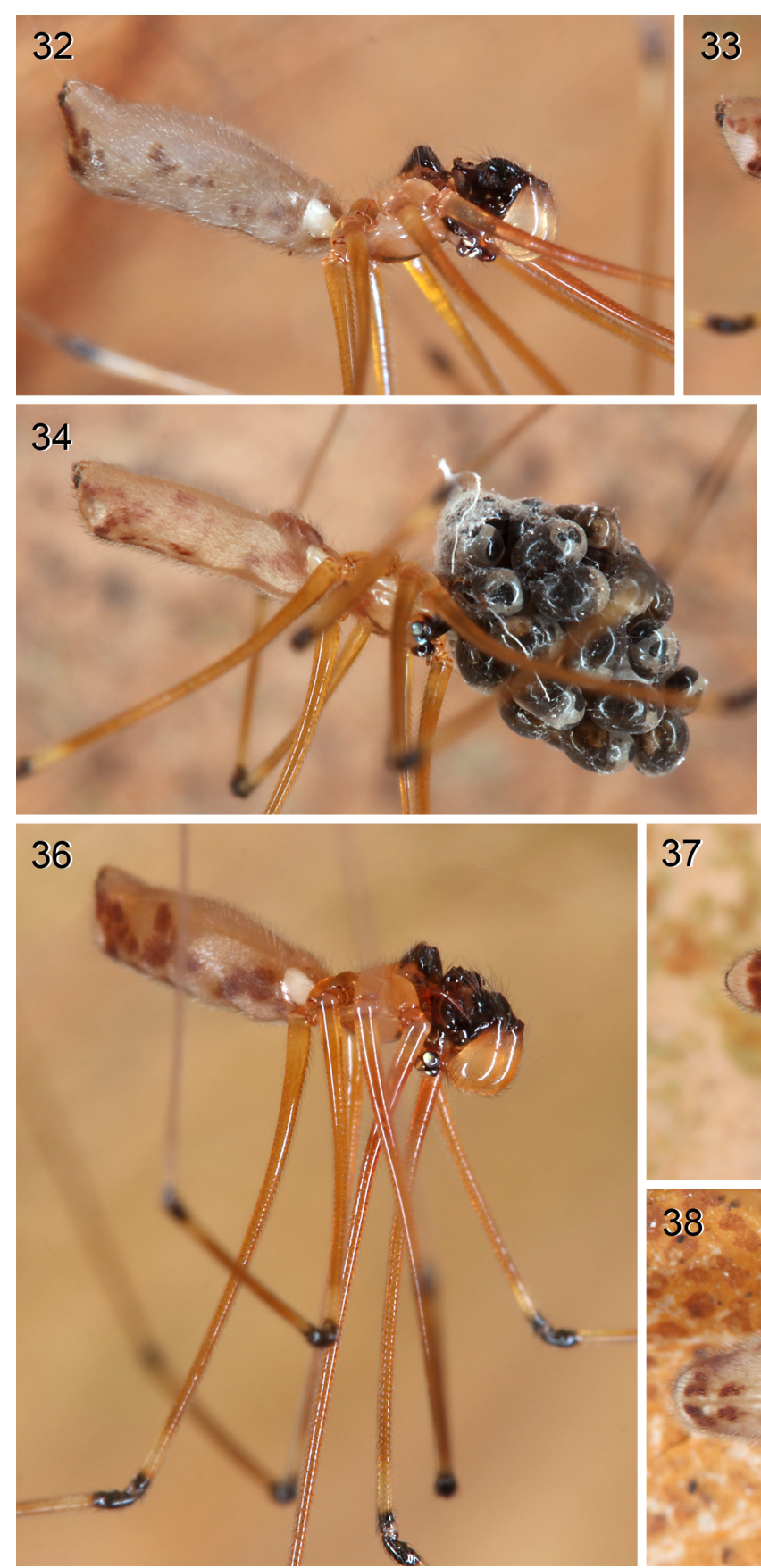
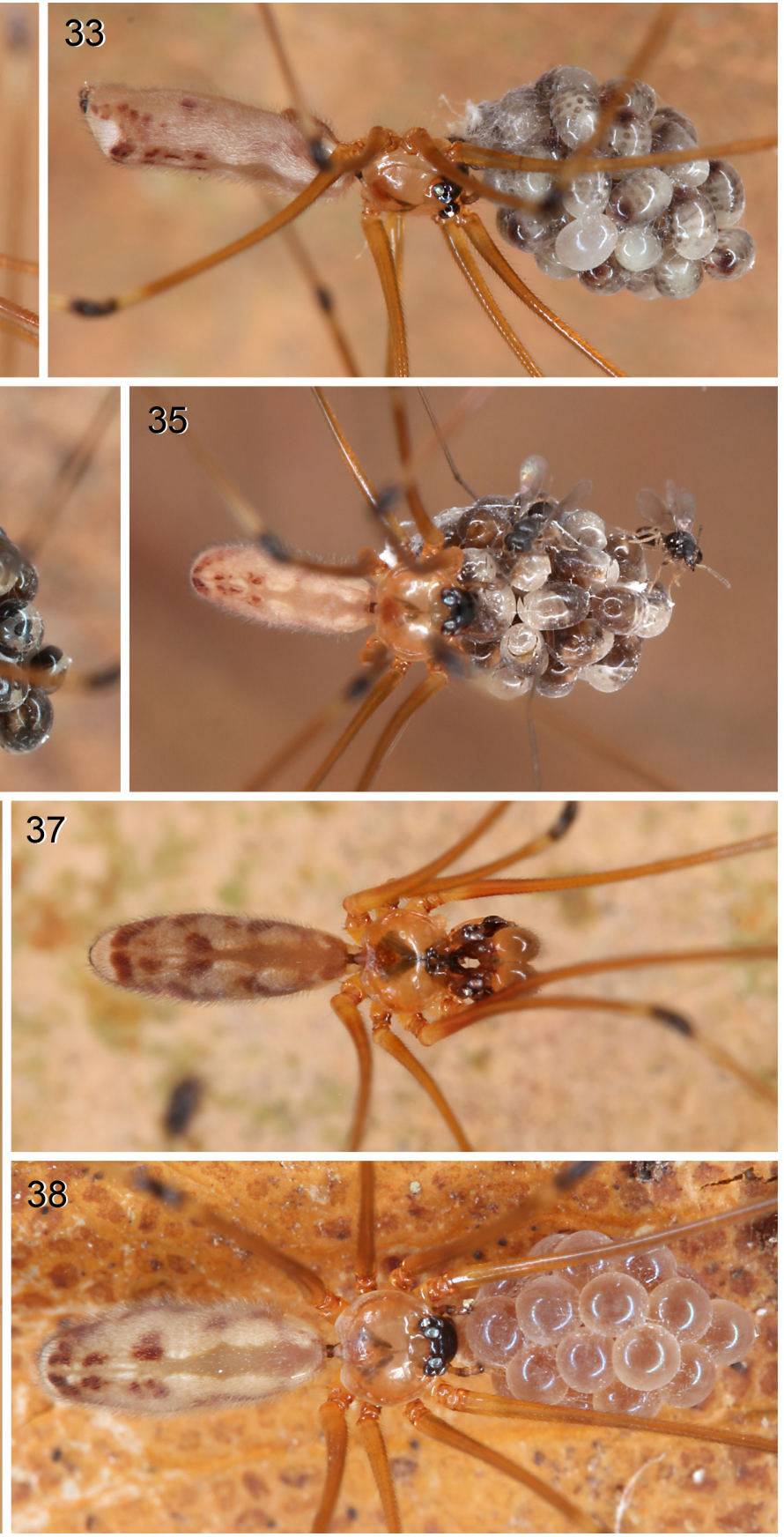

Figs 32-38. Live specimens. 32-35. Pholcus gombak Huber, 2011, Kemensah (32) and Gunung Liang (33-35), $\hat{O}, q$ with parasitized egg-sac seven days before eclosion of wasps (33), one day before eclosion (34), and at eclosion (35). 36-38. P. ledang Huber, 2011, Gunung Ledang, $\widehat{O}$ and $q$ with egg-sac. 

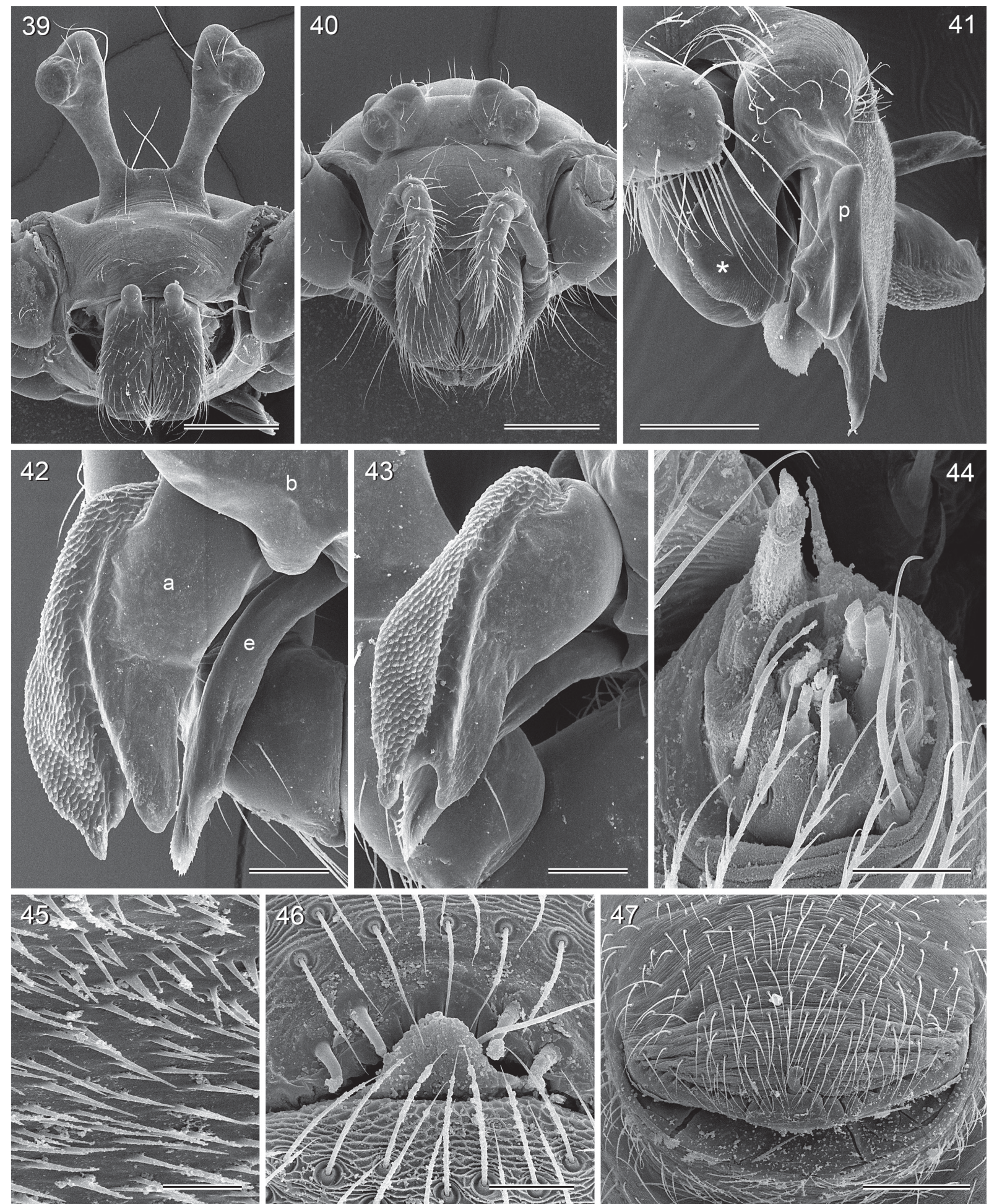

Figs 39-47. Pholcus gombak Huber, 2011, SEM micrographs (ZFMK, Ar 15701-02). 39-40. Male and female prosomata, frontal views. 41. Left procursus; asterisk marks large prolatero-dorsal process. 42 43. Right appendix and embolus, prolateral and prolatero-distal views. 44. Female ALS. 45. Cuticular processes on whitish retrolateral area of left procursus. 46. Male gonopore. 47. Epigynum, ventral view. Scale bars: $39-40=300 \mu \mathrm{m} ; 41,47=200 \mu \mathrm{m} ; 42,43=100 \mu \mathrm{m} ; 44=20 \mu \mathrm{m} ; 45=10 \mu \mathrm{m} ; 46=30 \mu \mathrm{m}$. 
Pholcus ledang Huber, 2011

Figs 36-38, 48-58

Pholcus ledang Huber, 2011: 180, figs 753-756, 781-783, 814-818 (ぷ+ ).

\section{Diagnosis}

Easily distinguished from most similar known relatives (other species of the $P$. ethagala group on the Malay Peninsula) by morphology of male palps (figs 814-815 in Huber 2011, Fig. 54; procursus with
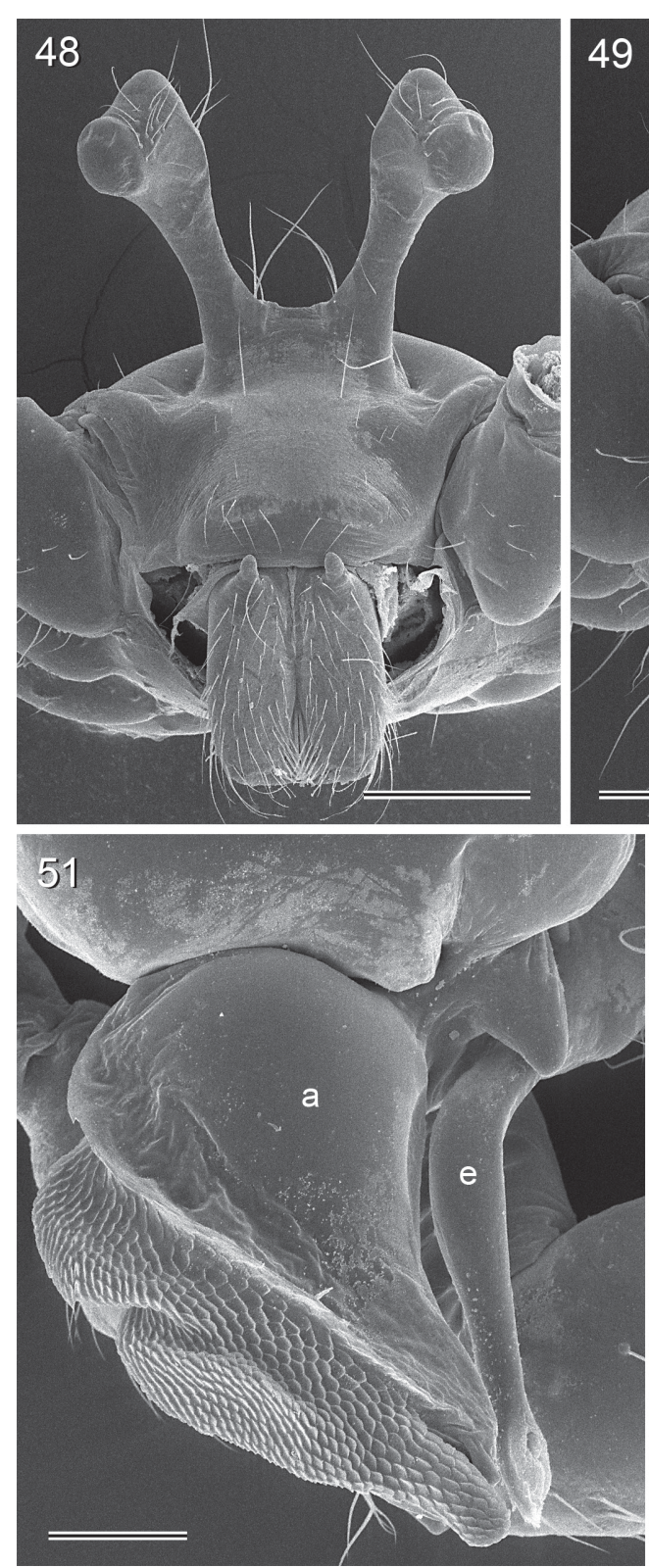
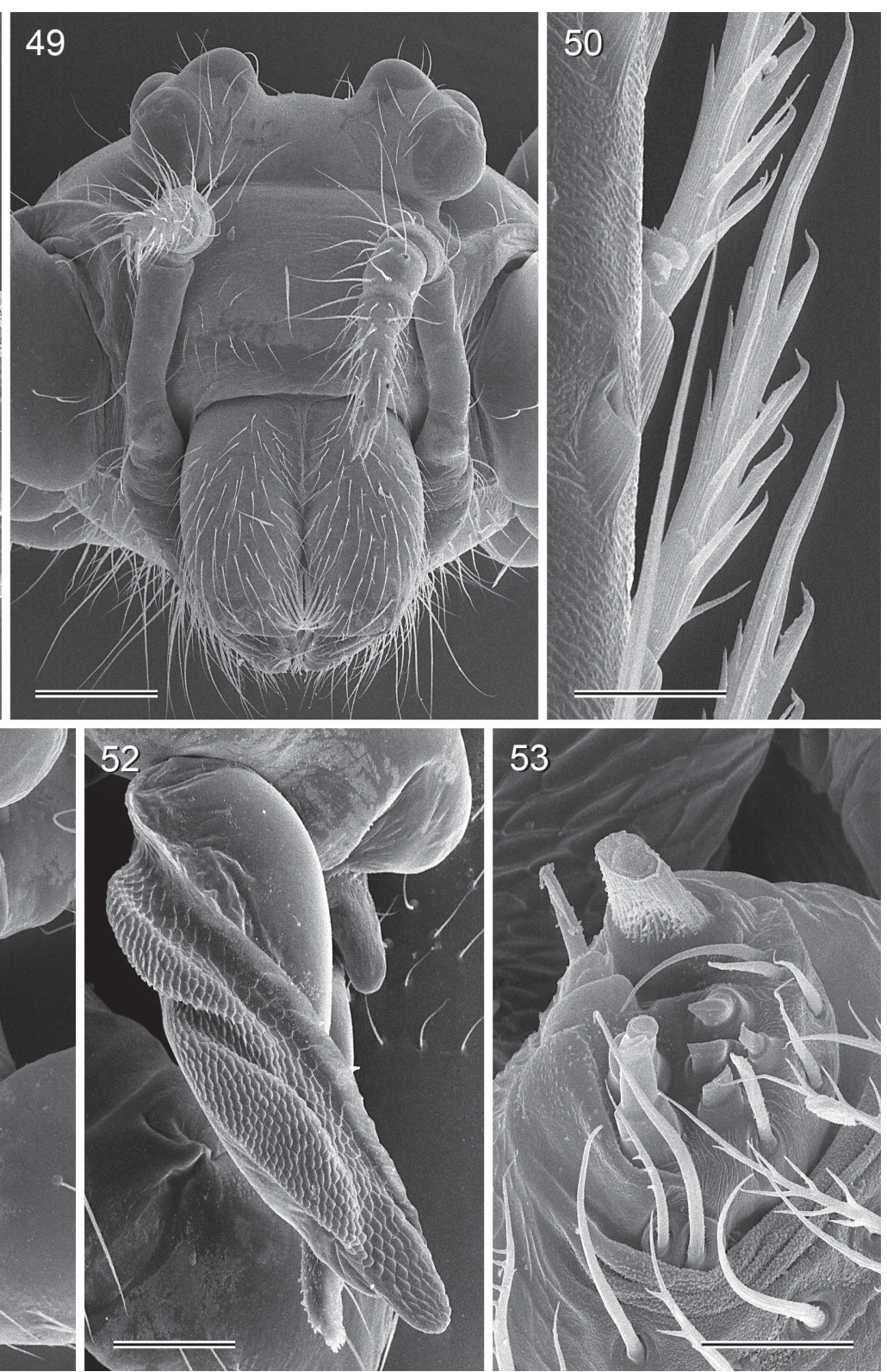

Figs 48-53. Pholcus ledang Huber, 2011, SEM micrographs (ZFMK, Ar 15704-05). 48-49. Male and female prosomata, frontal views. 50. Comb hairs on male tarsus 4. 51-52. Right appendix and embolus, prolateral and distal views. 53. Female ALS. Scale bars: $48=300 \mu \mathrm{m} ; 49=200 \mu \mathrm{m} ; 50=10 \mu \mathrm{m}$; $51-52=100 \mu \mathrm{m} ; 53=20 \mu \mathrm{m}$. 
distinctive pair of retrolateral ridges and complex distal elements), and by details of female internal genitalia (figs 817-818 in Huber 2011; large U-shaped anterior sclerite; small oval pore plates far apart).

\section{New material examined}

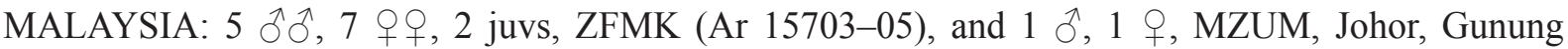
Ledang, forest near Puteri Falls $\left(2.355^{\circ} \mathrm{N}, 102.635^{\circ} \mathrm{E}\right), 110 \mathrm{~m}$ a.s.l., leaf litter, $17-18$ Feb. 2015 (B.A. Huber); 1 ภ, 4 우, 1 juv., in absolute ethanol, ZFMK (Mal 237, Mal 242), same data.

\section{Description - amendments}

Whitish area on procursus set with many small cuticular pointed processes (Fig. 56). Appendix with prolateral groove and dense cover of small scales (Figs 51, 52). Male gonopore with four epiandrous spigots (Fig. 57). ALS with one large widened, one pointed, and six smaller cylindrically-shaped spigots (Fig. 53). Tibia 1 in 5 males: 6.6-7.7 (mean 7.1); in 8 females: 5.0-6.0 (mean 5.5). Tarsus 4 comb-hairs as in Fig. 50.

\section{Natural history}

Specimens were found under tree logs and under dead leaves on the ground. They barely moved when disturbed, other than a short burst of low-amplitude vibration.
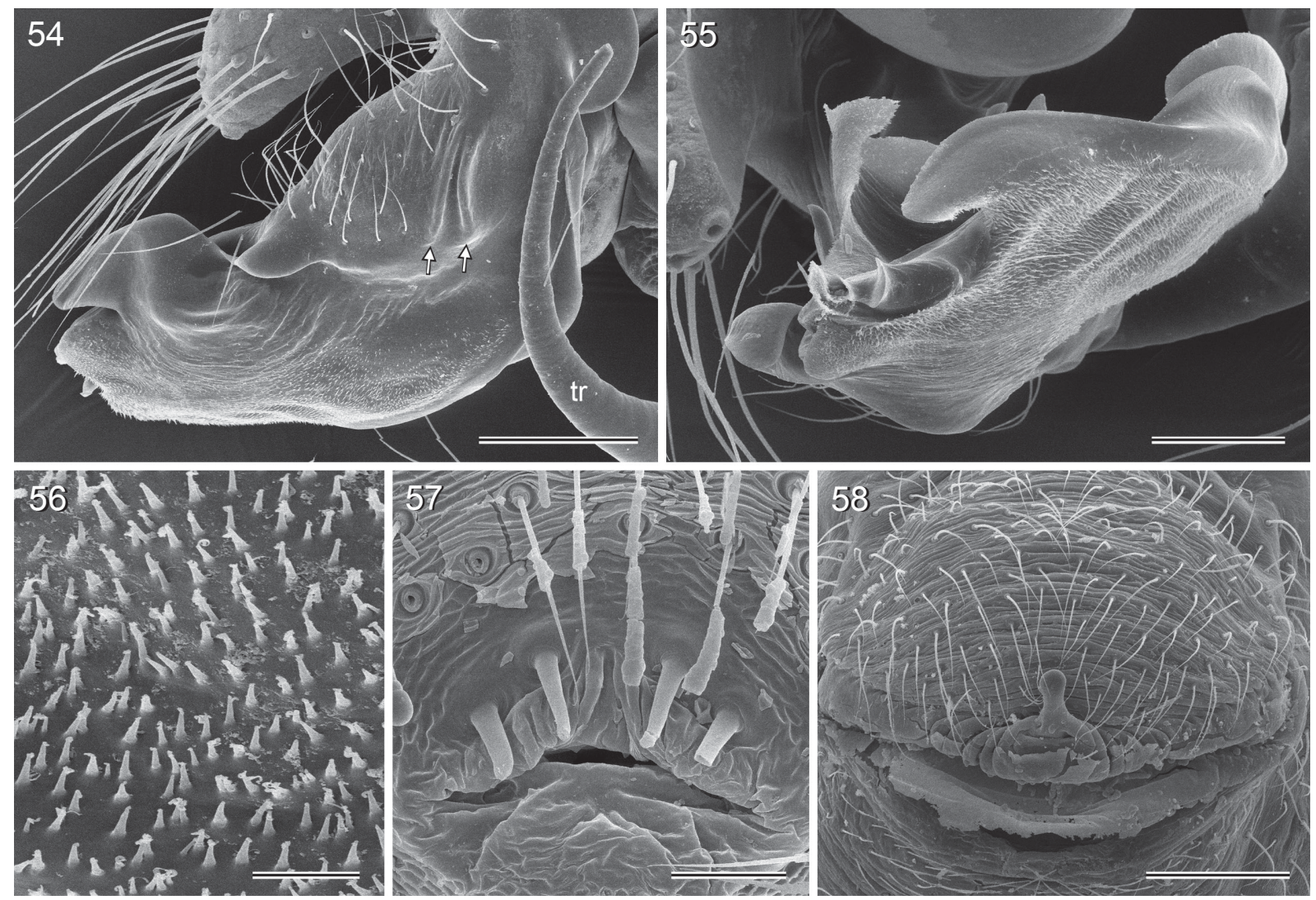

Figs 54-58. Pholcus ledang Huber, 2011, SEM micrographs (ZFMK, Ar 15704-05). 54. Left procursus, retrolateral view. 55. Right procursus, distal view. 56. Cuticular processes on whitish retrolateral area of left procursus. 57. Male gonopore. 58. Epigynum, ventral view. Scale bars: $54,58=200 \mu \mathrm{m}$; $55=100 \mu \mathrm{m} ; 56=10 \mu \mathrm{m} ; 57=30 \mu \mathrm{m}$. 
Pholcus bukittimah Huber sp. nov. urn:lsid:zoobank.org:act:93CDF3AF-2A6D-4AFE-926B-3FE43BBD495E

Figs 59-62, 67-71, 79, 87-89

\section{Diagnosis}

Easily distinguished from most similar known relatives (other species of the P. ethagala group on the Malay Peninsula) by morphology of male palps (Figs 67-68; extremely long curved male palpal trochanter apophysis; procursus with slender dorsal process and long whitish retrolateral area), and by details of female internal genitalia (Figs 70-71; anterior triangular sclerite; semicircular pore plates; posterior rectangular structure).
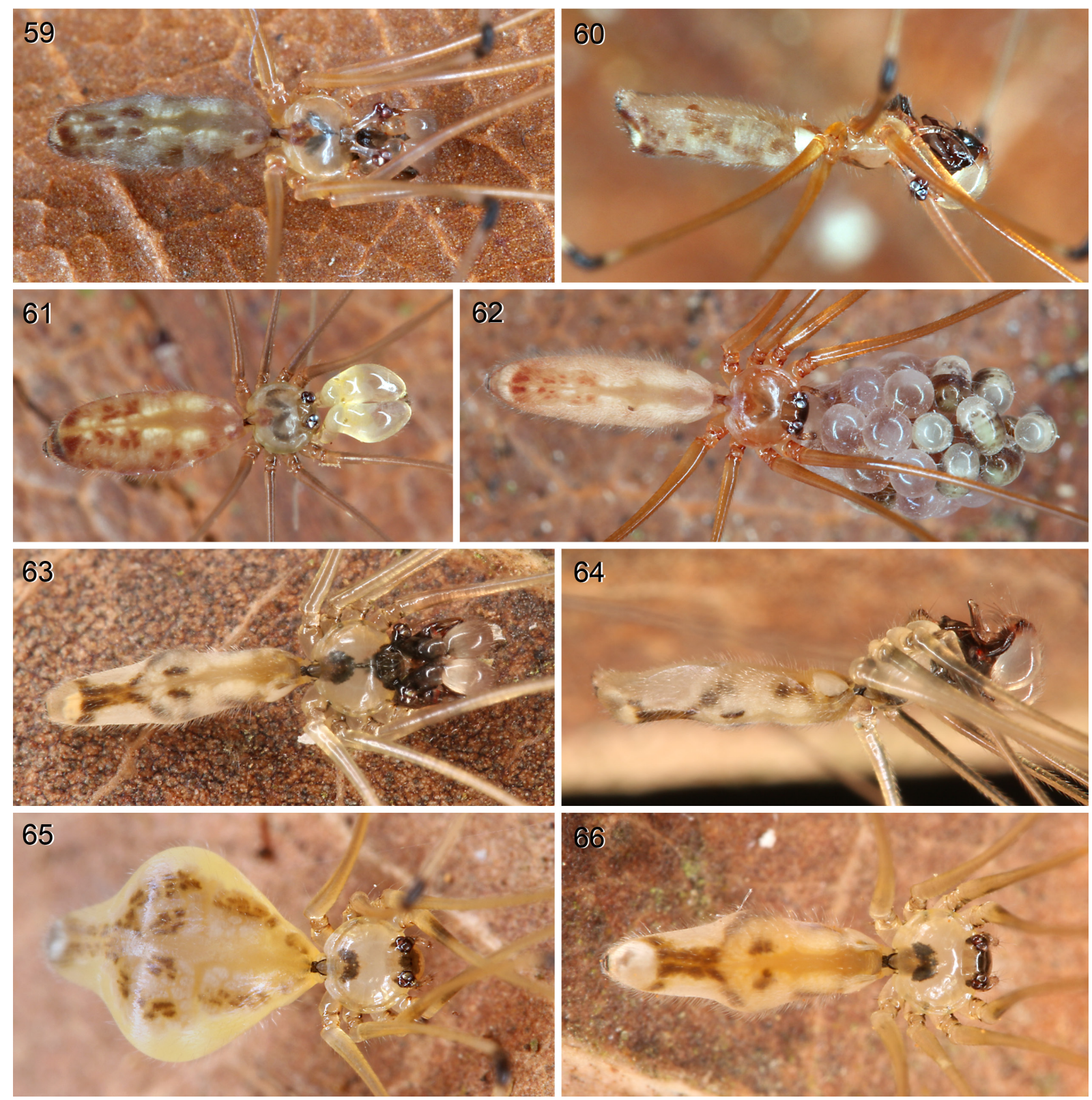

Figs 59-66. Live specimens. 59-62. Pholcus bukittimah Huber sp. nov., Dairy Farm, ô, penultimate $\widehat{\partial}$, and $q$ with partly parasitized egg-sac. 63-66. $P$. barisan Huber sp. nov., Bukit Barisan, $\delta^{\lambda}$ and $q+$ with variably expanded abdomens. 


\section{Etymology}

The species is derived from the type locality; noun in apposition.

\section{Material examined}

\section{Holotype}

SINGAPORE: ${ }^{\Uparrow}$, ZFMK (Ar 15706), Bukit Timah, Dairy Farm Nature Park $\left(1.360^{\circ} \mathrm{N}, 103.778^{\circ} \mathrm{E}\right)$, $50 \mathrm{~m}$ a.s.l., leaf litter near Wallace Trail, 15 Feb. 2015 (B.A. Huber, J.K.H. Koh).

\section{Other material}

SINGAPORE: $1 \hat{\jmath}, 1$ 을 ZFMK (Ar 15707), same data as holotype; 2 우, in absolute ethanol, ZFMK (Mal 212, Mal 256), same data.

\section{Description}

\section{Male (holotype)}

Measurements. Total body length 3.5, carapace width 0.95. Leg 1: $29.5(6.9+0.4+7.0+13.4+1.8)$, tibia 2: 4.0, tibia 3: 2.5, tibia 4: 3.9; tibia $1 \mathrm{~L} / \mathrm{d}: 84$. Distance PME-PME $440 \mu \mathrm{m}$, diameter PME $115 \mu \mathrm{m}$, distance PME-ALE $35 \mu \mathrm{m}$; AME absent.

Color. Carapace pale ochre-yellow with light brown median V-mark posteriorly, clypeus light brown, ocular area not darkened; sternum whitish; legs ochre-yellow with darker brown patellae and tibiametatarsus joints; abdomen gray with some black marks dorsally and laterally.

Body. Habitus as in Figs 59-60; ocular area raised and each triad on long stalk (Fig. 79); carapace without median furrow; clypeus unmodified; sternum wider than long $(0.62 / 0.48)$, unmodified.

Chelicerae. As in Fig. 69, with single pair of frontal proximal apophyses; without distal modification; without stridulatory ridges.

PALPS. As in Figs 67-68; coxa unmodified; trochanter with very long curved retrolatero-ventral apophysis and small weakly sclerotized retrolateral process; femur with indistinct ventral humps proximally and distally; tarsus with large rounded elongation; procursus complex, proximal part with distinctive dorsal process; hinged distal part with large whitish area retrolaterally and transparent fringed processes prolaterally; bulb with very large appendix, long slender embolus, and small uncus-like process partly sclerotized as continuation of proximal bulbal sclerite.

LEGS. Without spines and curved hairs; few vertical hairs; retrolateral trichobothrium on tibia 1 at $2 \%$; prolateral trichobothrium absent on tibia 1 , present on other tibiae; tarsus 1 pseudosegments very indistinct, apparently irregular.

Male (variation)

Tibia 1 in other male: 7.7 .

\section{Female}

In general similar to male (Fig. 62) but eye triads not on stalks and much closer together than in male (PME-PME distance: $200 \mu \mathrm{m}$ ); clypeus and ocular area frontally dark brown, with pair of small black marks in area of AME (but without lenses). Tibia 1 in 1 female: 5.8. Epigynum weakly sclerotized (Fig. 87), only posterior rim slightly more sclerotized, with small dark 'knob' (Fig. 70); large anterior triangular internal sclerite visible through cuticle; internal genitalia as in Figs 71, 88-89. 


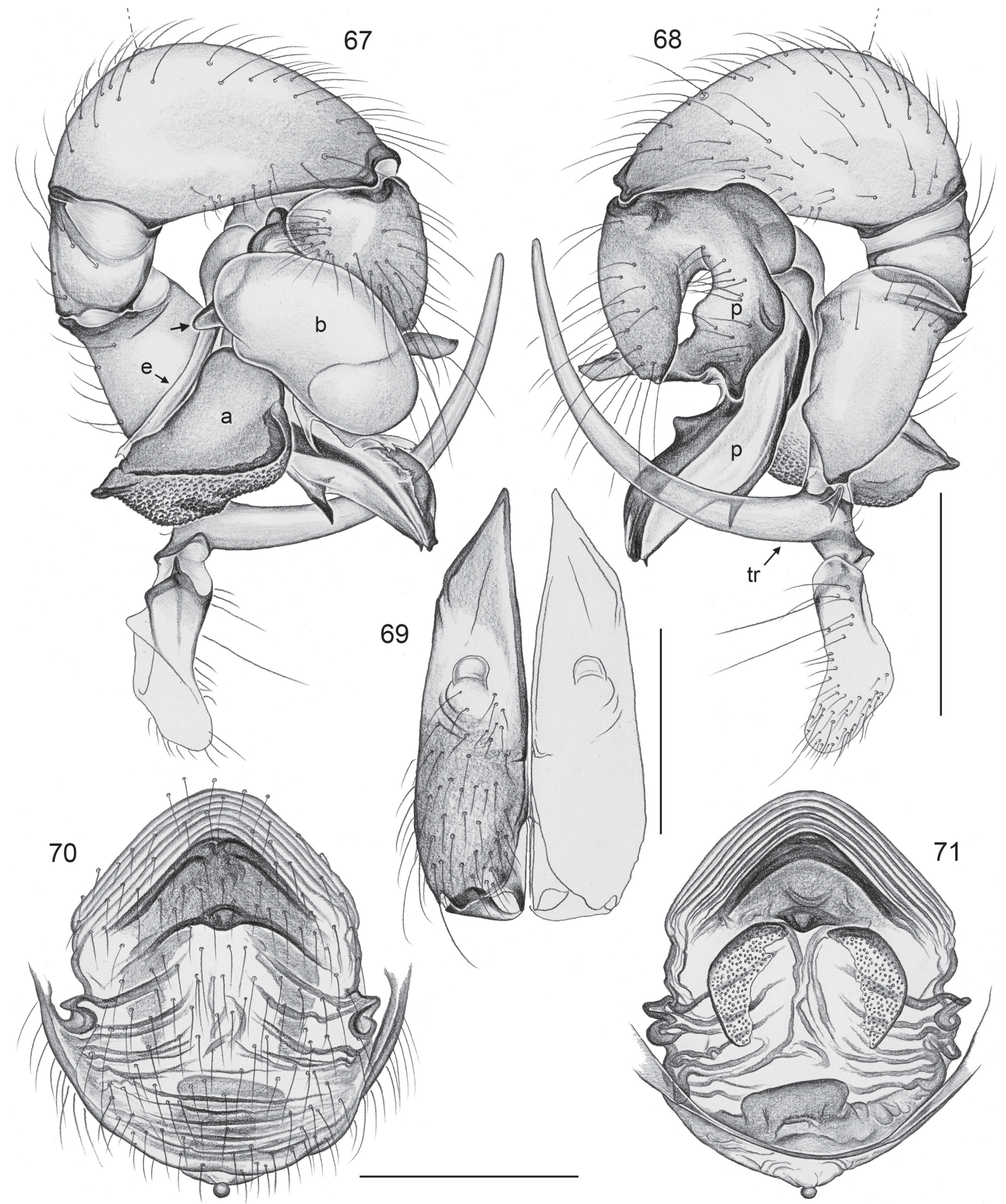

Figs 67-71. Pholcus bukittimah Huber sp. nov. (ZFMK, Ar 15706-07). 67-68. Left male palp, prolateral and retrolateral views; arrow points at uncus-like process of proximal bulbal sclerite. 69. Male chelicerae, frontal view. 70-71. Cleared female genitalia, ventral and dorsal views. Scale bars: $67-68,70-71=0.5 \mathrm{~mm}$; $69=0.3 \mathrm{~mm}$. 


\section{Natural history}

All specimens were found in an area of the forest where large dead leaves on the ground were abundant. They built their domed webs closely attached to the undersides of the leaves. A few eggs in an egg-sac of one female were parasitized by Idris wasps (Fig. 62).

\section{Distribution}

Known from type locality in Singapore only (Fig. 1).

Pholcus barisan Huber sp. nov. urn:Isid:zoobank.org:act:20779D81-A780-4FBD-92F6-78BD201FE319

Figs 63-66, 72-76, 80, 90-92

\section{Diagnosis}

Easily distinguished from most similar known relatives (representatives of the P. ethagala group on the Malay Peninsula) by morphology of male palps (Figs 72-73; very long dorsal process of procursus; relative straight male palpal trochanter apophysis similar to P. uludong Huber sp. nov. and P. phui but shorter; shape of relatively small appendix), by modified male clypeus (pair of small dark processes; Fig. 80), by male eye stalks directed more towards lateral (Fig. 80), and by details of female internal genitalia (Figs 75, 76; anterior undulating sclerite; large posterior semicircular structure).

\section{Etymology}

The species name is derived from the type locality; noun in apposition.

\section{Material examined}

\section{Holotype}

INDONESIA: ${ }^{\curvearrowright}$, ZFMK (Ar 15708), Sumatra, Lampung, Bukit Barisan (5.528 $\left.{ }^{\circ} \mathrm{S}, 104.424^{\circ} \mathrm{E}\right), 550$ $600 \mathrm{~m}$ a.s.l., forest near road, leaf litter, 24 Oct. 2009 (S. Sutono).

\section{Other material}

INDONESIA: 6 + $q, 3$ juvs, ZFMK (Ar 15709), same data as holotype; 4 q $q, 1$ juv., in absolute ethanol, ZFMK (Ind 153), same data.

\section{Description}

\section{Male (holotype)}

MeAsurements. Total body length 3.3, carapace width 0.9. Leg 1: $33.2(7.6+0.4+7.7+15.6+1.9)$, tibia 2: 4.5, tibia 3: 2.6, tibia 4: 4.0; tibia 1 L/d: 96. Distance PME-PME $510 \mu \mathrm{m}$, diameter PME $100 \mu \mathrm{m}$, distance PME-ALE $\sim 30 \mu \mathrm{m}$; AME absent.

Color. Carapace pale ochre-yellow with large dark brown mark posteriorly, dark median line, ocular area, stalks and clypeus also dark brown; irregular black marks in place of AME; sternum whitish; legs ochre-yellow with darker brown to black patellae and tibia-metatarsus joints; abdomen ochre-gray with some darker marks dorsally and laterally.

BoDy. Habitus as in Figs 63-64; ocular area raised, each triad on long stalk directed laterad and dorsad (Fig. 80); carapace without median furrow; clypeus with pair of small dark processes at rim; sternum wider than long $(0.60 / 0.53)$, unmodified.

Chelicerae. As in Fig. 74, with single pair of frontal proximal apophyses; without distal modification; without stridulatory ridges. 


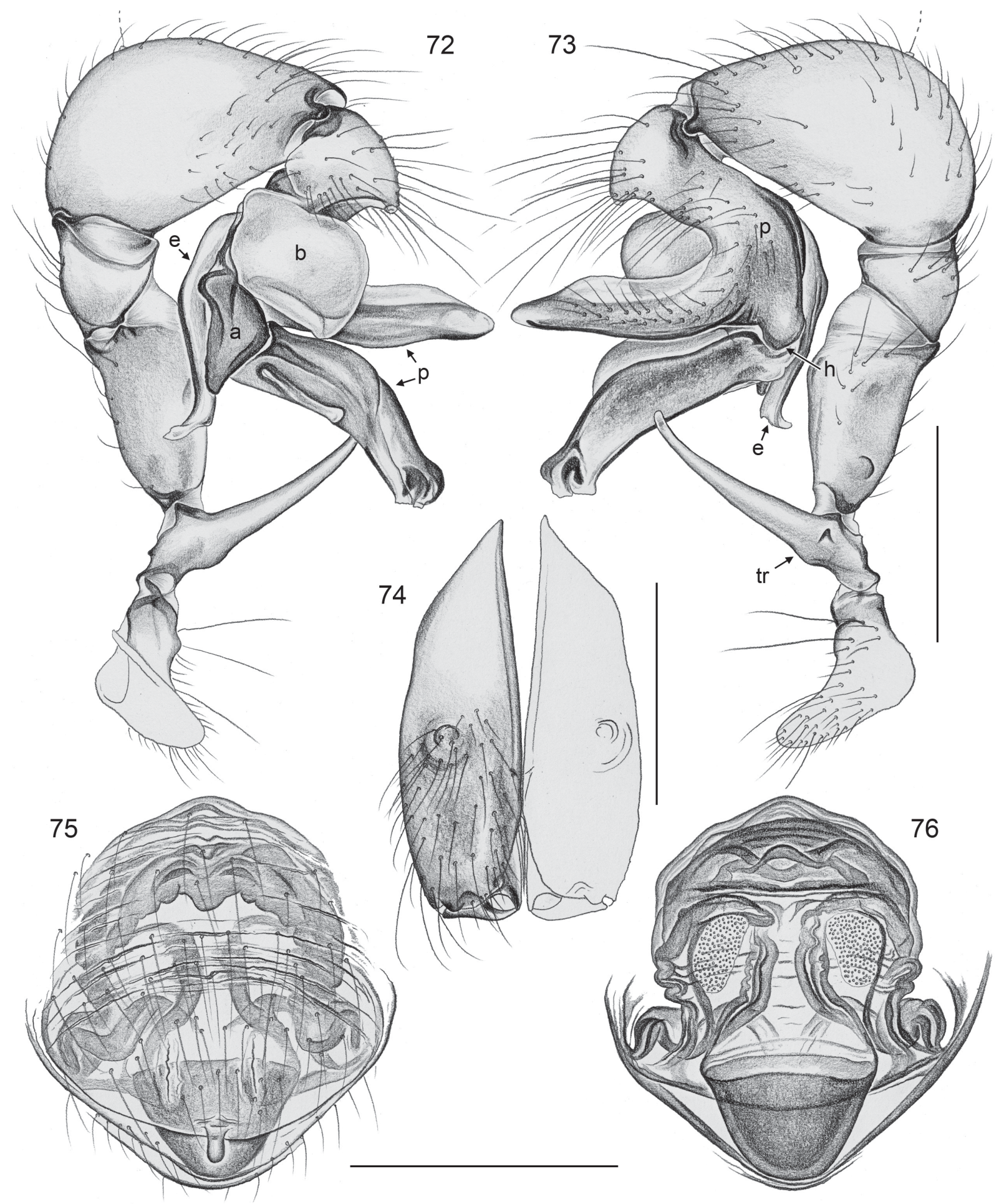

Figs 72-76. Pholcus barisan Huber sp. nov. (ZFMK, Ar 15708-09). 72-73. Left male palp, prolateral and retrolateral views. 74. Male chelicerae, frontal view. 75-76. Cleared female genitalia, ventral and dorsal views. Scale bars: $72-73,75-76=0.5 \mathrm{~mm} ; 74=0.3 \mathrm{~mm}$. 

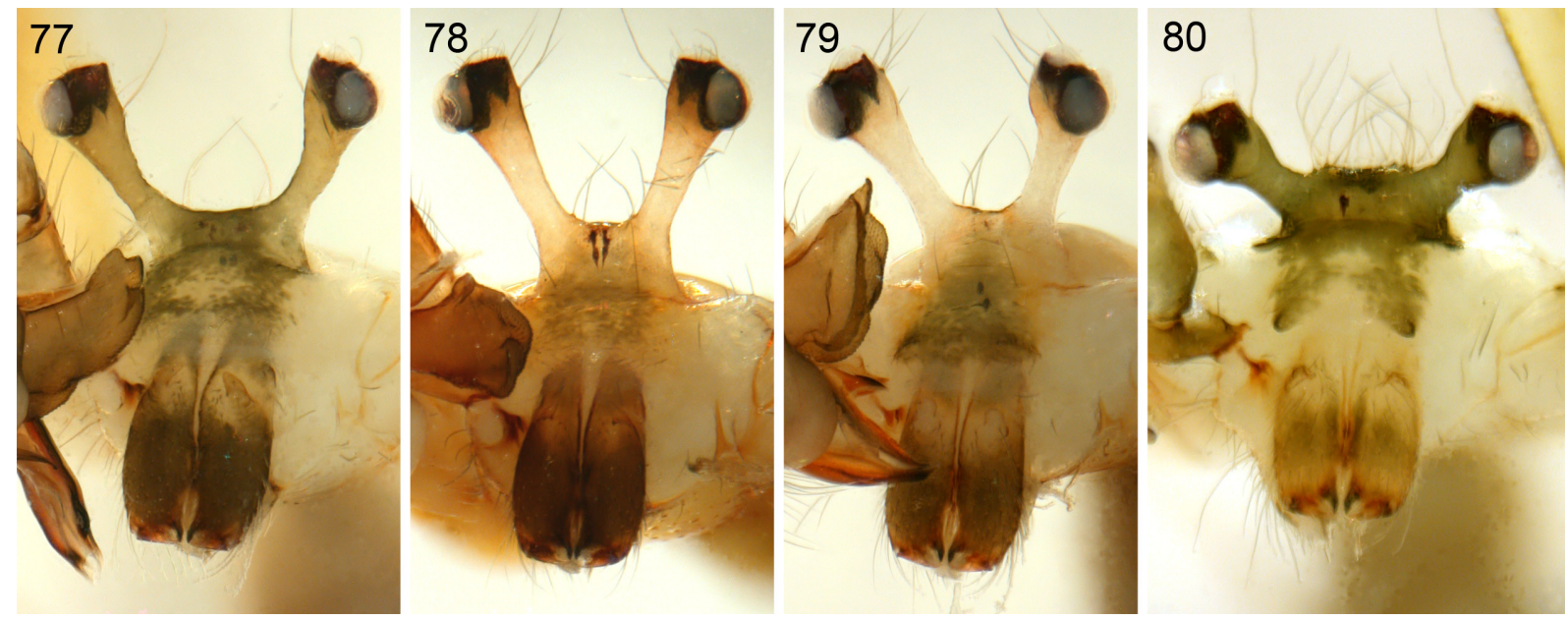

Figs 77-80. Male prosomata, frontal views. 77. Pholcus tanahrata Huber sp. nov. 78. P. uludong Huber sp. nov. 79. P. bukittimah Huber sp. nov. 80. P. barisan Huber sp. nov.
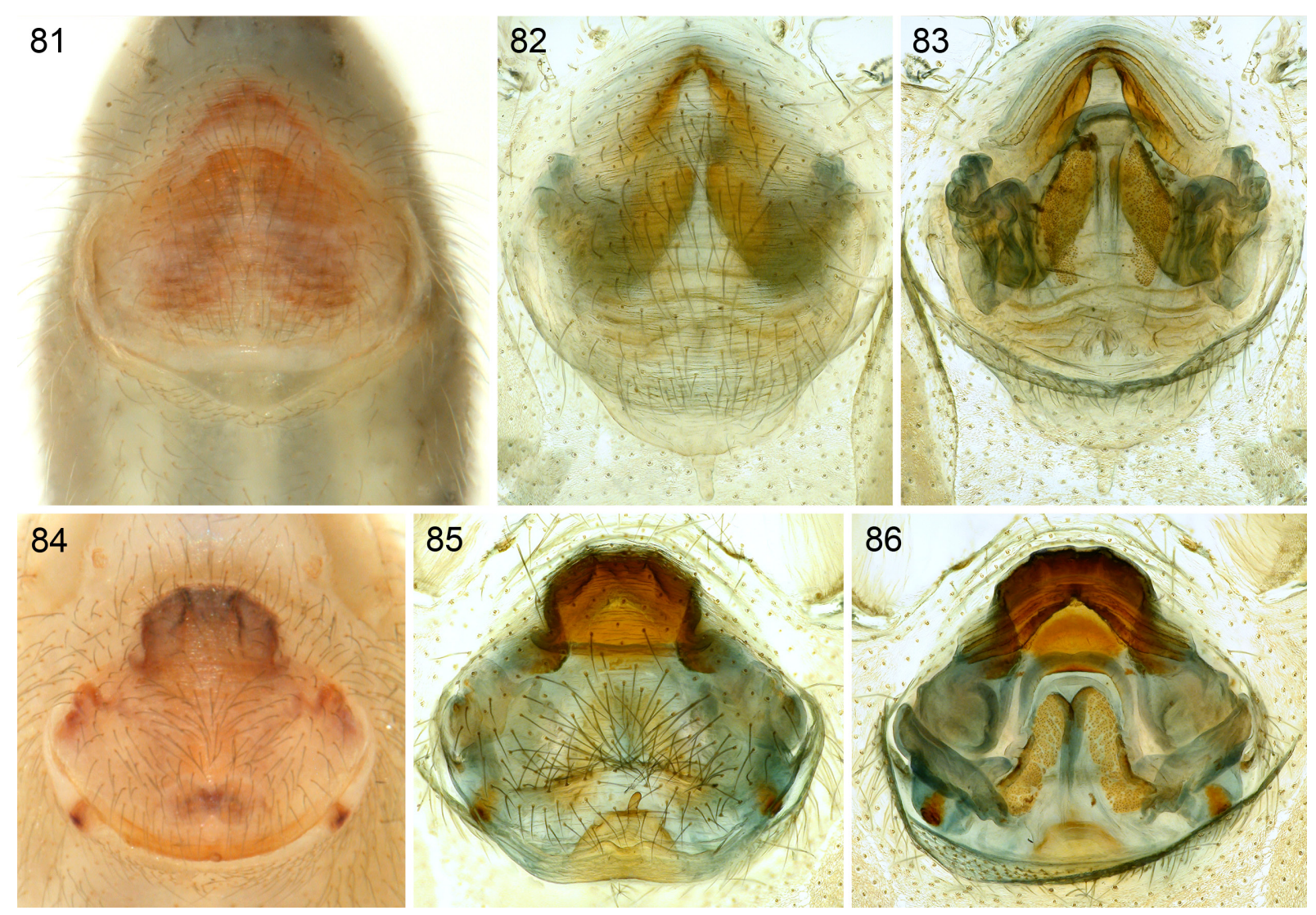

Figs 81-86. Epigyna, ventral views, and cleared female genitalia, ventral and dorsal views. 8183. Pholcus tanahrata Huber sp. nov. (ZFMK, Ar 15692). 84-86. P. uludong Huber sp. nov. (ZFMK, Ar 15696). 
PALPS. As in Figs 72-73; coxa with indistinct ventral hump; trochanter with very long almost straight retrolatero-ventral apophysis and small retrolateral process; femur with indistinct retrolateral hump; tarsus without dorsal elongation; procursus complex, proximal part with distinctive dorsal process forming retrolateral groove distally, ventral side heavily sclerotized, dorsal side semitransparent; hinged distal part with large prolatero-dorsal flap and weakly sclerotized prolateral process lying parallel to procursus; bulb with rather simple appendix, long slender embolus, without uncus.

LEGS. Without spines and curved hairs; few vertical hairs; retrolateral trichobothrium on tibia 1 at $3 \%$; prolateral trichobothrium absent on tibia 1, present on other tibiae; tarsus 1 pseudosegments very indistinct, apparently irregular.

\section{Female}

In general similar to male (Figs 65-66) but eye triads not on stalks and much closer together than in male (PME-PME distance: $240 \mu \mathrm{m}$ ); dark posterior mark on carapace smaller than in male, without median dark line on carapace; with pair of small black marks in area of AME (but without lenses); clypeus unmodified and only in upper third dark brown. Tibia 1 in 6 females: 6.0-6.9 (mean 6.4). Some females (and juveniles) with laterally strongly widened abdomen (Fig. 65). Epigynum weakly
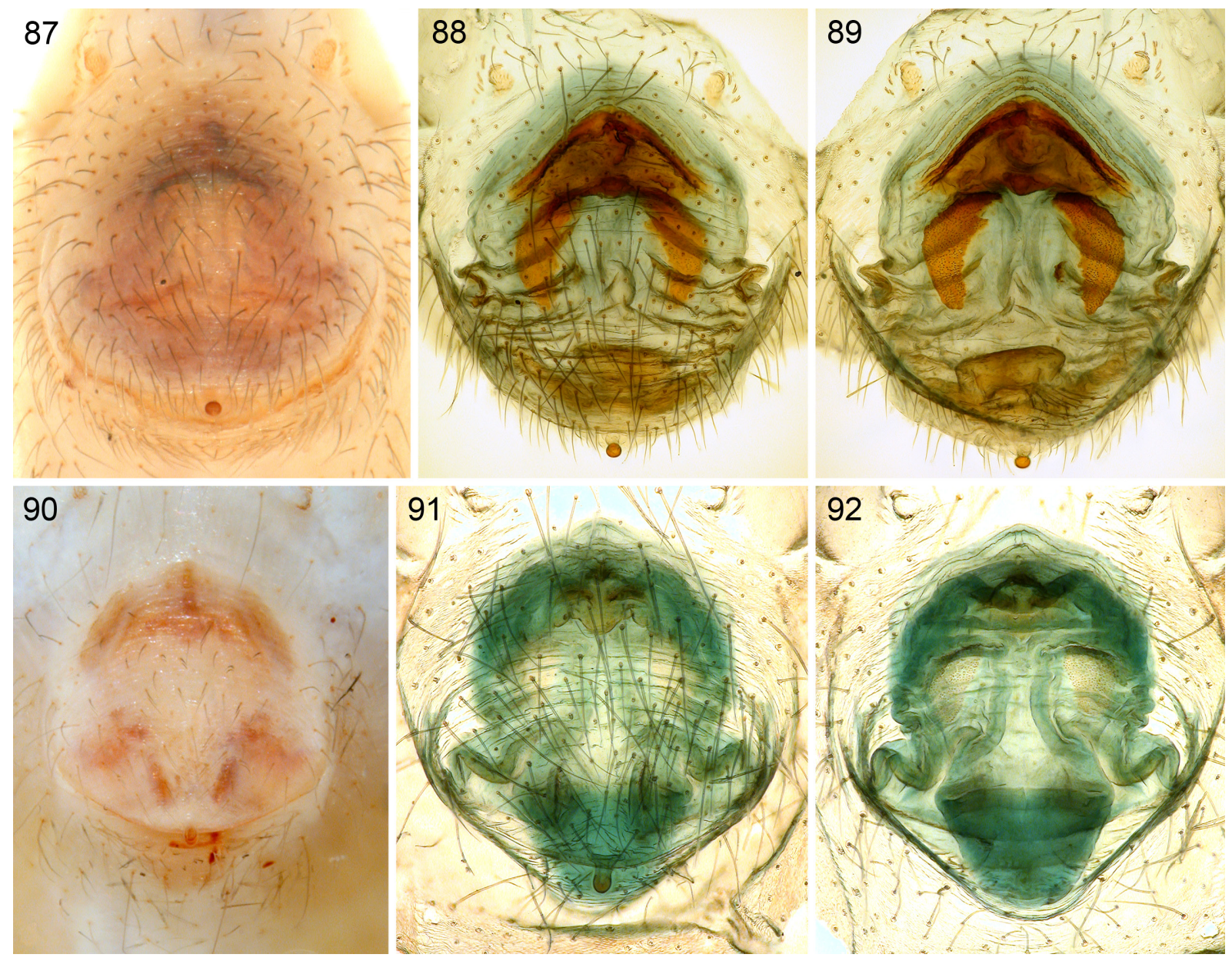

Figs 87-92. Epigyna, ventral views, and cleared female genitalia, ventral and dorsal views. 8789. Pholcus bukittimah Huber sp. nov. (ZFMK, Ar 15707). 90-92. P. barisan Huber sp. nov. (ZFMK, Ar 15709). 
sclerotized (Fig. 90), with small 'knob' at posterior rim (Fig 75); internal anterior arc undulating, visible through cuticle; internal genitalia as in Figs 76, 91-92.

\section{Natural history}

All specimens were found under large dead leaves on the ground. They hung in domed sheet webs closely attached to the leaf surface. They barely moved when disturbed and were not seen to vibrate.

\section{Distribution}

Known from type locality in Sumatra only (Fig. 1).

Pholcus tambunan species group

\section{Diagnosis}

The two species included in this group are medium-sized, long-legged spiders (body length $\sim 4$, male leg 1 length: 35-40), distinguished from other species groups in Pholcus by combination of the following characters: elongate abdomen angular dorso-posteriorly (Figs 94, 98); six eyes; male chelicerae with distinctive distal apophyses (flat sclerites without modified hairs; Figs 103, 108, 120); most palpal structures unusually long (in particular genital bulb; Figs 101, 121); male bulb without uncus; epigynum weakly sclerotized, scape directed towards anterior with terminal 'knob' (Figs 104, 123); female internal genitalia with pair of highly distinctive three-layered telescopic tubes (Figs 105, 124).

\section{Description}

See individual descriptions of the two very similar species below.

\section{Composition}

Only the two species described below.

\section{Natural history}

Both species were found on the undersides of live leaves where they built very fine webs tightly attached to the leaf surface. Both species were frequently seen to share their webs with cecidomyiid flies. For further information, see descriptions below.

\section{Distribution}

The P. tambunan group is restricted to northern Borneo (Fig. 1).

$$
\begin{aligned}
& \text { Pholcus tambunan Huber sp. nov. } \\
& \text { urn:Isid:zoobank.org:act:5FD747F9-A402-4C77-BFC0-B26BDCDB10B5 }
\end{aligned}
$$

Figs 93-96, 101-119, 125-127

\section{Diagnosis}

Easily distinguished from most similar known relative (P. bario Huber sp. nov.) by morphology of male palps (Figs 101-102; shorter trochanter apophysis; wider femur; distinctive structures on tip of procursus), by different shapes of frontal cheliceral apophyses (Fig. 103), and by shorter epigynal scape (Figs 104, 119).

\section{Etymology}

The species is named for Tambunan, the town close to the type locality; noun in apposition. 


\section{Material examined}

\section{Holotype}

MALAYSIA-BORNEO: Õ, ZFMK (Ar 15710), Sabah, Crocker Range between Kota Kinabalu and Tambunan, S-slope, forest along river $\left(5.783^{\circ} \mathrm{N}, 116.339^{\circ} \mathrm{E}\right), 1430-1480 \mathrm{~m}$ a.s.l., on underside of leaf, 3 Aug. 2014 (B.A. Huber, S.B. Huber).

\section{Other material}

MALAYSIA-BORNEO: $4 \hat{\jmath}, 3+q$, ZFMK (Ar 15711-12), and $1 \hat{\jmath}, 1$, , SMK, same data as holotype; 2 우, 3 juvs, in absolute ethanol, ZFMK (Bor 172), same data. 2 $\sigma^{\lambda}, 1$,, ZFMK (Ar 15713), Crocker Range between Kota Kinabalu and Tambunan, N-slope, forest along river $\left(5.834^{\circ} \mathrm{N}, 116.336^{\circ} \mathrm{E}\right), 1600$ $\mathrm{m}$ a.s.1., undersides of leaves, 3 Aug. 2014 (B.A. Huber, S.B. Huber); 2 우, in absolute ethanol, ZFMK (Bor 167), same data; 2 $\widehat{\jmath}, 14$ $q$, 1 juv., ZFMK (Ar 15714-15), Mt. Kinabalu, forest along Silau Silau Trail $\left(6.010-6.017^{\circ} \mathrm{N}, 116.537-116.543^{\circ} \mathrm{E}\right), 1550-1650 \mathrm{~m}$ a.s.l., on undersides of leaves, 6 Aug. 2014 (B.A. Huber, S.B. Huber); 4 우, 2 juvs, in absolute ethanol, ZFMK (Bor 212), same data; 1 ○,
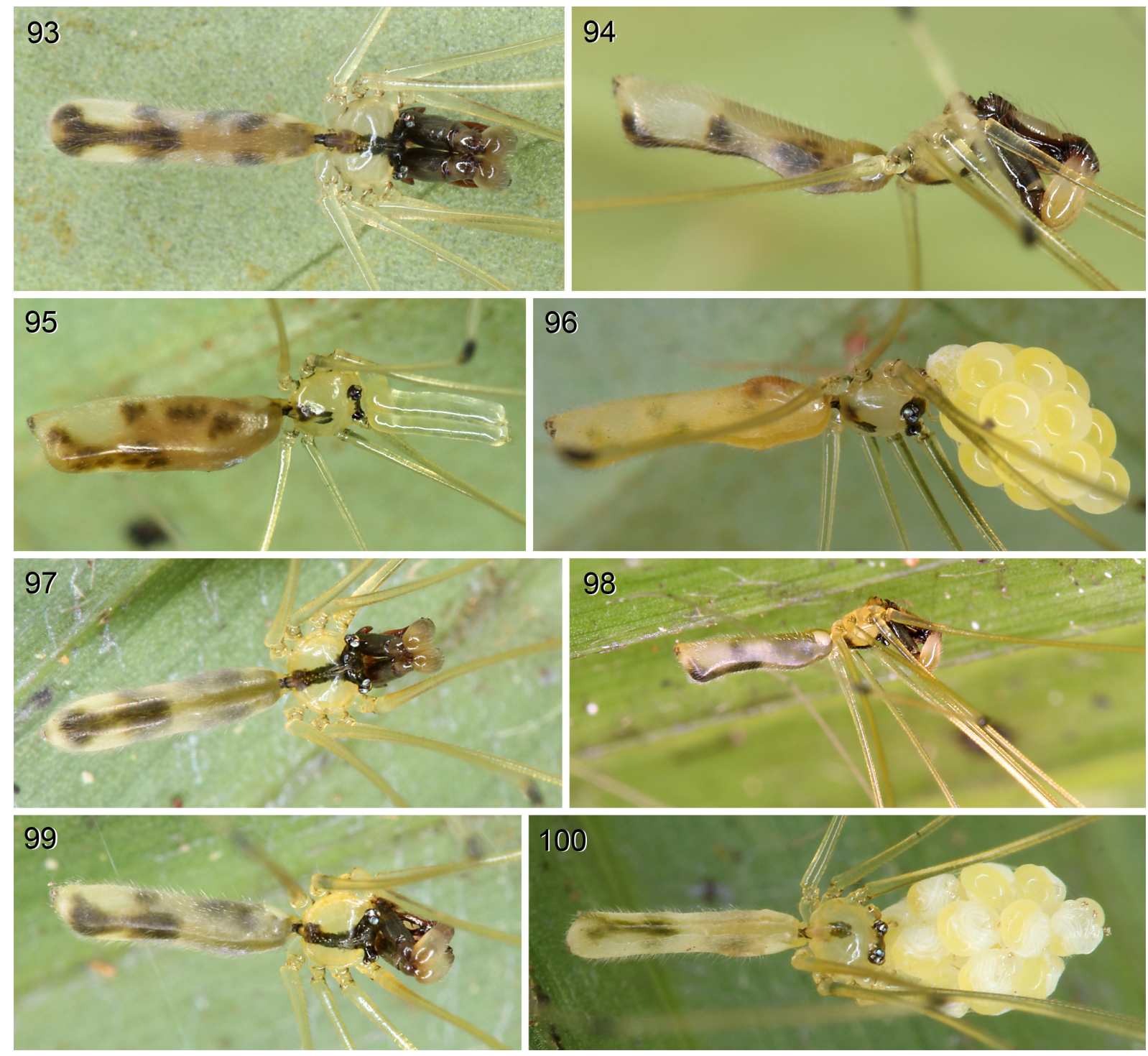

Figs 93-100. Live specimens. 93-96. Pholcus tambunan Huber sp. nov., Crocker Range, §̊, penultimate $\hat{\partial}$, and $q$ with egg-sac. 97-100. P. bario Huber sp. nov., Bario, $\hat{\partial}$ and $q$ with egg-sac. 


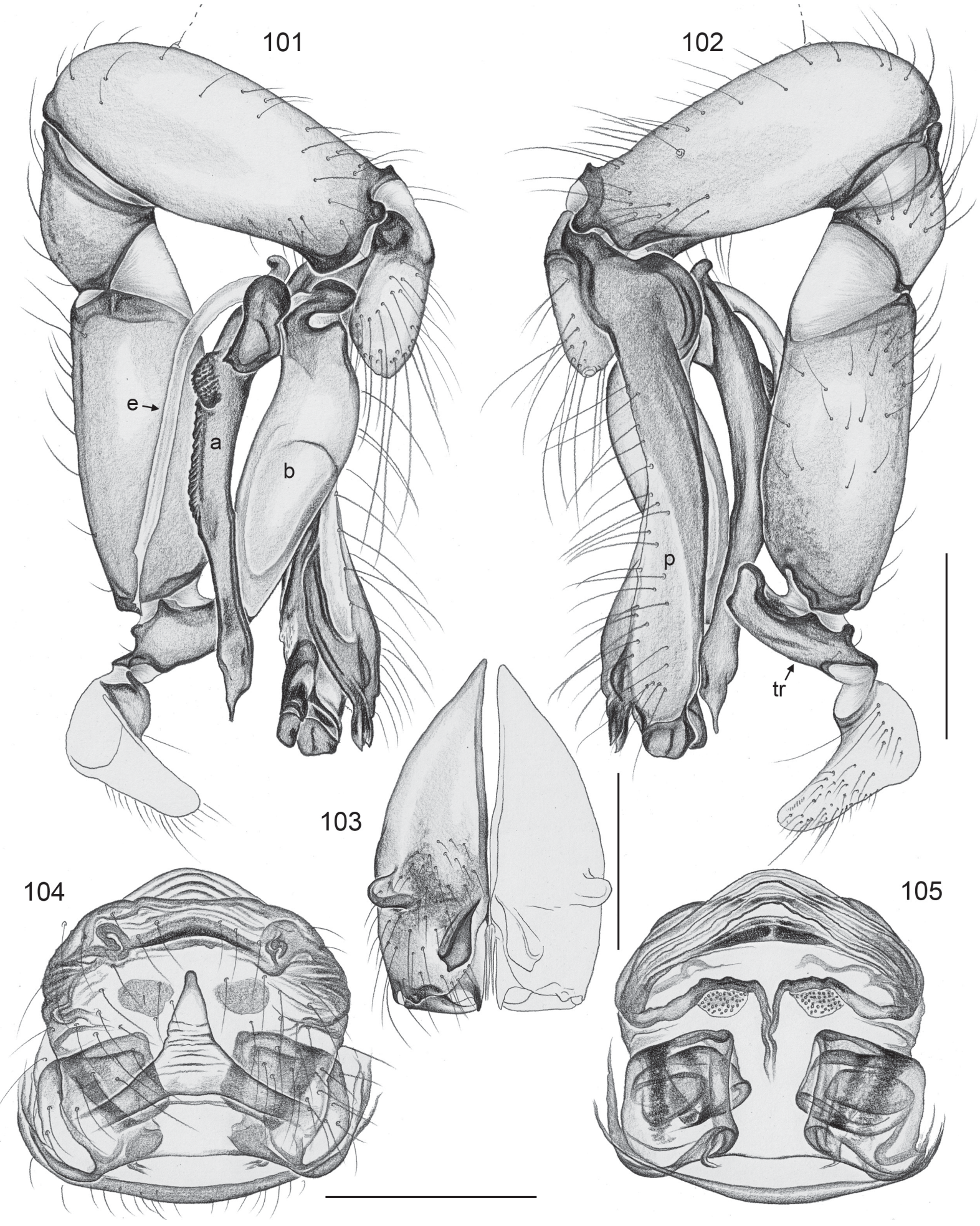

Figs 101-105. Pholcus tambunan Huber sp. nov. (ZFMK, Ar 15711-12). 101-102. Left male palp, prolateral and retrolateral views. 103. Male chelicerae, frontal view. 104-105. Cleared female genitalia, ventral and dorsal views. Scale bars: $101-102,104-105=0.5 \mathrm{~mm} ; 103=0.3 \mathrm{~mm}$. 

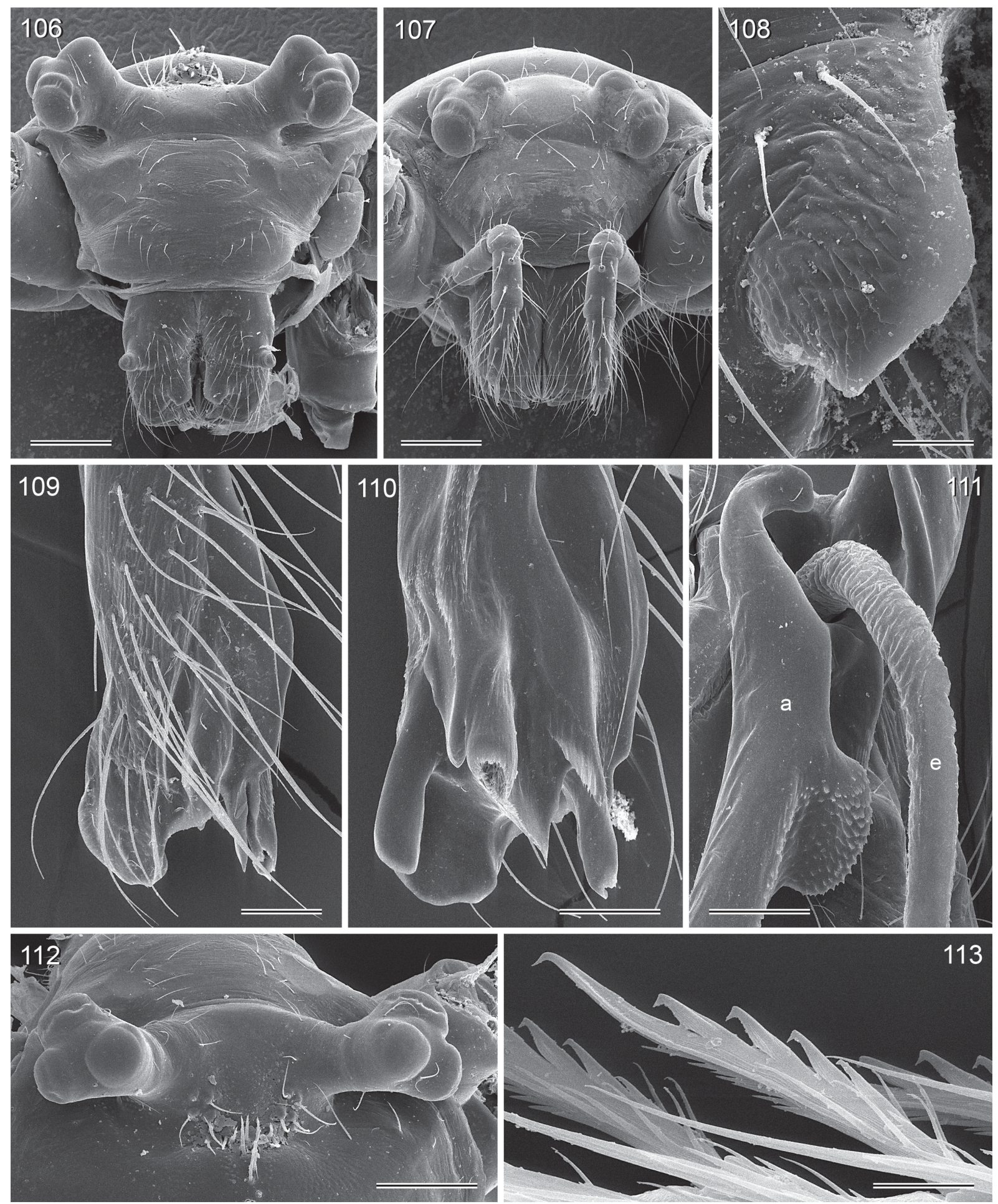

Figs 106-113. Pholcus tambunan Huber sp. nov., SEM micrographs (ZFMK, Ar 15711, 15715). 106-107. Male and female prosomata, frontal views. 108. Right male cheliceral apophysis. 109. Right procursus, retrolateral view. 110. Left procursus, prolateral view. 111. Proximal parts of left appendix and embolus. 112. Male ocular area, dorsal view. 113. Comb-hairs on male tarsus 4. Scale bars: 106$107,112=200 \mu \mathrm{m} ; 108=20 \mu \mathrm{m} ; 109-111=100 \mu \mathrm{m} ; 113=10 \mu \mathrm{m}$. 
1, , AMNH, Mt. Kinabalu, 1550 m a.s.1., 24 Jul. 1980 (C.L. \& P.R. Deeleman); 1 Oे, RMNH, same data

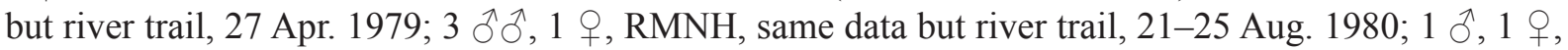
RMNH, same data but 1-5 May 1991.

\section{Assigned tentatively}

MALAYSIA-BORNEO: 1 ( (abdomen only), RMNH, Sepilok, $25 \mathrm{~km}$ E Sandakan [5.87 N, 117.94르. 1 Oct. 1980 (P. Zborowski).

\section{Description}

\section{Male (holotype)}

MeAsurements. Total body length 4.1, carapace width 1.0. Leg 1: $37.3(8.8+0.4+8.8+17.0+2.3)$, tibia 2: 5.6, tibia 3: 3.3, tibia 4: 5.0; tibia $1 \mathrm{~L} / \mathrm{d}$ : 100. Distance PME-PME $450 \mu \mathrm{m}$, diameter PME 130 $\mu \mathrm{m}$, distance PME-ALE $\sim 35 \mu \mathrm{m}$; no trace of AME.

Color. Carapace whitish with dark median mark widening anteriorly and including ocular area and clypeus in upper part and laterally; sternum whitish; legs pale ochre-yellow with dark brown patellae and
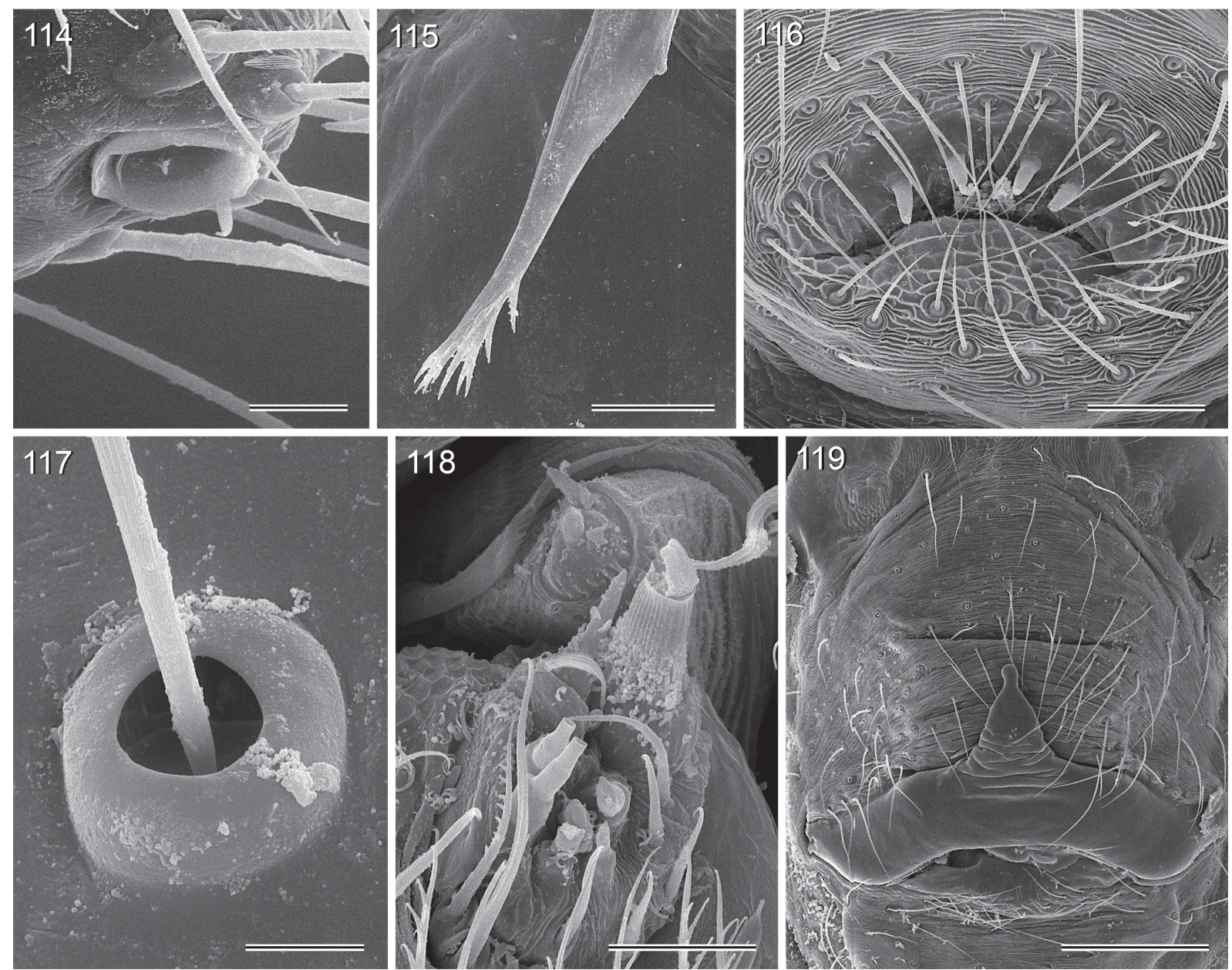

Figs 114-119. Pholcus tambunan Huber sp. nov., SEM micrographs (ZFMK, Ar 15711, 15715). 114. Male left palpal tarsal organ. 115. Tip of left embolus. 116. Male gonopore. 117. Base of trichobothrium on male palpal tibia. 118. Female ALS. 119. Epigynum, ventral view. Scale bars: $114,118=20 \mu \mathrm{m} ; 115=$ $50 \mu \mathrm{m} ; 116=40 \mu \mathrm{m} ; 117=8 \mu \mathrm{m} ; 119=200 \mu \mathrm{m}$. 
tibia-metatarsus joints; abdomen pale ochre-gray with black marks dorsally and laterally, monochromous ventrally.

BoDy. Habitus as in Figs 93-94; ocular area slightly raised, each triad on additional short stalk directed towards lateral (Fig. 106); carapace without median furrow; clypeus unmodified; sternum wider than long (0.70/0.54), unmodified. Gonopore with four epiandrous spigots (Fig. 116).

Chelicerae. As in Fig. 103, with distinctive pair of frontal apophyses (large flat plates, distally drawn out into small tip; Fig. 108) and rounded lateral humps; without modified hairs; without stridulatory ridges.

PALPS. As in Figs 101-102; coxa unmodified; trochanter with strong ventral apophysis; femur cylindrical, with indistinct prolateral hump proximally; tibia with distinctively elevated dorso-distal rim; tarsal organ as in Fig. 114; procursus with strong ventral 'knee', with distinctive small prolateral sclerotized process at 1/3 length, distal half with large whitish area retrolaterally, tip complex with distinctive sclerites (Figs 109, 110); bulb elongated, long appendix with distinctive prolateral process provided with small teeth, further teeth along ventral rim, proximal processes of appendix 'guiding' embolus between them (Fig. 111); embolus long and weakly sclerotized, tip as in Fig. 115.

LEGS. Without spines and curved hairs; few vertical hairs; retrolateral trichobothrium on tibia 1 at $2 \%$; prolateral trichobothrium absent on tibia 1, present on other tibiae; tarsus 1 pseudosegments not seen in dissecting microscope. Tarsus 4 comb-hairs as in Fig. 113.

Male (variation)

Tibia 1 in 7 other males: 8.2-9.3 (mean 8.6).

\section{Female}

In general similar to male (Fig. 96) but carapace mark only in posterior half; ocular area dark as in male but clypeus light. Eye triads much closer together than in male (Fig. 107; PME-PME distance: $265 \mu \mathrm{m}$ ). Dark marks on abdomen less distinct or even absent. Tibia 1 in 18 females: 6.2-7.2 (mean 6.7). Epigynum weakly sclerotized (Fig. 125), wide transversal plate with scape directed towards anterior (Fig. 104); dark internal arch and lateral posterior structures visible through cuticle; internal genitalia as in Figs 105, 126, 127, with pair of highly distinctive three-layered telescopic tubes. ALS with one large widened, one pointed, and six smaller cylindrically-shaped spigots (Fig. 118). The female from Sepilok is assigned tentatively because no male is known from this locality.

\section{Natural history}

The spiders were found on the undersides of live leaves about 50-200 $\mathrm{cm}$ above the ground. They built barely visible silk platforms directly attached to the leaf surface rather than the 'usual' pholcid domes. Several webs were occupied (in addition to the spider) by large numbers of Diptera (probably Cecidomyiidae, not collected).

\section{Distribution}

Known from three localities in northeastern Borneo (Sabah) (Fig. 1; but note that the single specimen from Sepilok is assigned tentatively). 


\section{Pholcus bario Huber sp. nov. urn:Isid:zoobank.org:act:D680CB67-1525-4263-B8D4-8E44E587C51E}

Figs $97-100,121-124,128-130$

\section{Diagnosis}

Easily distinguished from most similar known relative (P. tambunan Huber sp. nov.) by morphology of male palps (Figs 121-122; longer trochanter apophysis; more slender femur; distinctive structures on tip of procursus), by different shapes of frontal cheliceral apophyses (Fig. 120), and by longer epigynal scape (Fig. 123).

\section{Etymology}

The species name is derived from the type locality; noun in apposition.

\section{Material examined}

\section{Holotype}

MALAYSIA-BORNEO: ${ }^{\lambda}$, ZFMK (Ar 15716), Sarawak, Bario, forest along river W of town $\left(3.736^{\circ} \mathrm{N}\right.$, 115.437-115.443 ${ }^{\circ}$ E), $1150-1250 \mathrm{~m}$ a.s.l., on underside of leaf, 30 Jul. 2014 (B.A. Huber, S.B. Huber).

\section{Other material}

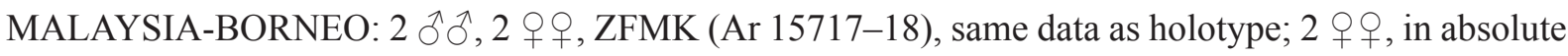
ethanol, ZFMK (Bor 232), same data.

\section{Description}

\section{Male (holotype)}

MEAsuREMENTs. Total body length 3.9, carapace width 0.9. Leg 1: $34.5(8.1+0.4+8.2+15.5+2.3)$, tibia 2: 5.3, tibia 3: 3.2, tibia 4: 4.7; tibia $1 \mathrm{~L} / \mathrm{d}$ : 104. Distance PME-PME $370 \mu \mathrm{m}$, diameter PME $95 \mu \mathrm{m}$, distance PME-ALE $\sim 35 \mu \mathrm{m}$; no trace of AME.

CoLOR. Carapace whitish with dark median mark widening anteriorly and including ocular area and clypeus in upper part and laterally; sternum whitish; legs pale ochre-yellow with dark brown patellae and tibia-metatarsus joints; abdomen pale ochre-gray with black marks dorsally and laterally, monochromous ventrally.

BoDy. Habitus as in Figs 97-99; ocular area slightly raised, each triad on additional short stalk directed towards lateral (Fig. 120); carapace without median furrow; clypeus unmodified; sternum wider than long $(0.64 / 0.52)$, unmodified.

Chelicerae. As in Fig. 120, with distinctive pair of frontal apophyses (large flat curved plates) and small rounded lateral humps; without modified hairs; without stridulatory ridges.

PALPS. As in Figs 121-122; coxa unmodified; trochanter with strong ventral apophysis; femur cylindrical, with two small retrolateral humps proximally and small ventral hump at half length; procursus with strong ventral 'knee', with distinctive small prolateral sclerotized process at $1 / 3$ length (arrow in Fig. 121), distal half with large whitish area retrolaterally, tip complex with distinctive sclerites; bulb elongated, long appendix with distinctive prolateral process provided with small teeth, further teeth along ventral rim, proximal processes of appendix 'guiding' embolus between them; embolus long and weakly sclerotized.

Legs. Without spines and curved hairs; few vertical hairs; retrolateral trichobothrium on tibia 1 at $2 \%$; prolateral trichobothrium absent on tibia 1, present on other tibiae; tarsus 1 pseudosegments not seen in dissecting microscope. 


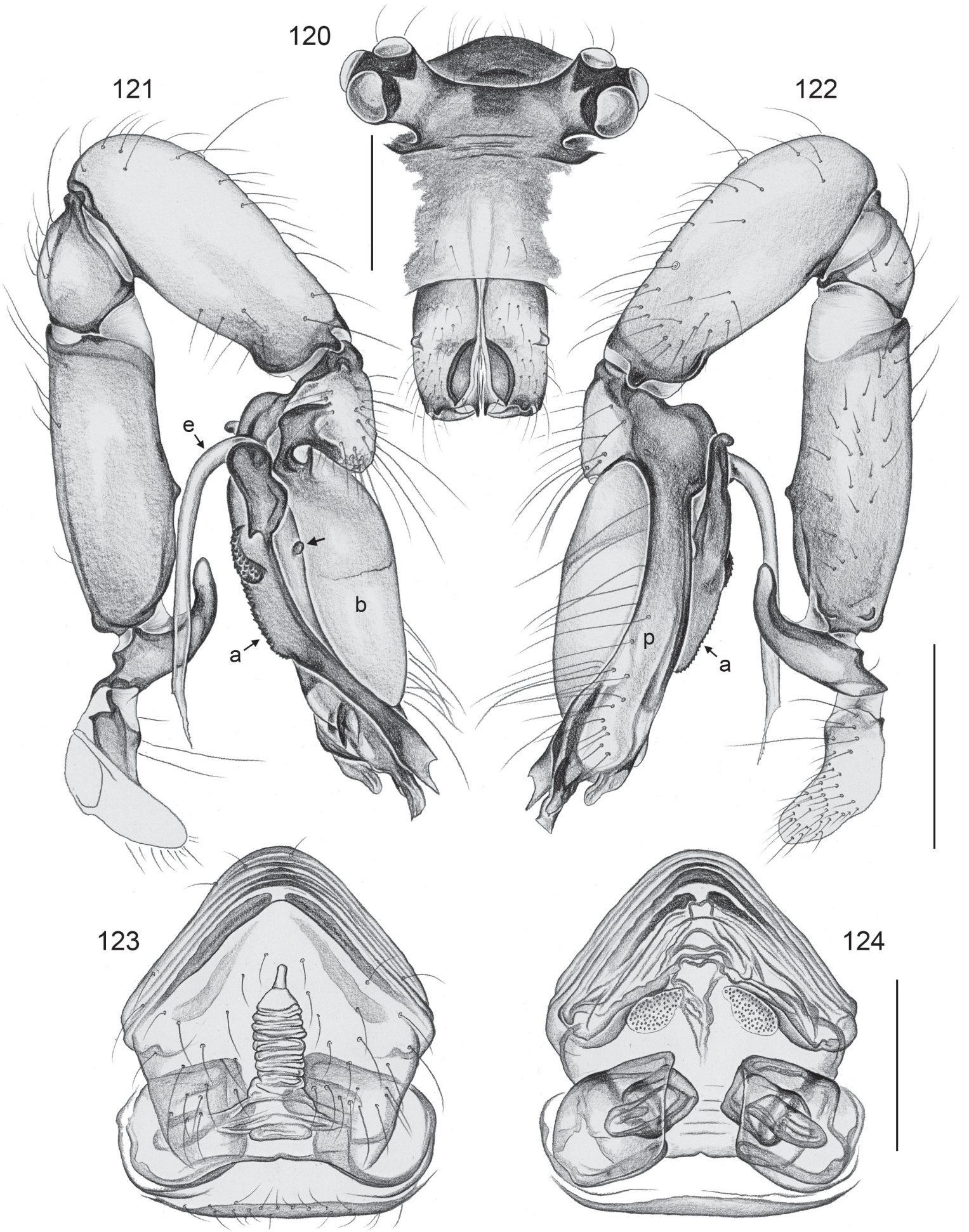

Figs 120-124. Pholcus bario Huber sp. nov. (ZFMK, Ar 15717-18). 120. Male prosoma, frontal view. 121-122. Left male palp, prolateral and retrolateral views; arrow points at prolateral finger-shaped process of procursus. 123-124. Cleared female genitalia, ventral and dorsal views. Scale bars: 120, $123-124=0.3 \mathrm{~mm} ; 121-122=0.5 \mathrm{~mm}$. 
Male (variation)

Tibia 1 in 2 other males: 7.8, 8.0.

\section{Female}

In general similar to male (Fig. 100) but carapace mark only in posterior half; ocular area dark as in male but clypeus light. Eye triads closer together than in male (PME-PME distance: $230 \mu \mathrm{m}$ ). Dark marks on abdomen less distinct. Tibia 1 in 2 females: 6.6 (both). Epigynum weakly sclerotized (Fig. 128), wide transversal plate with long scape directed towards anterior (Fig. 123); dark internal arch and lateral posterior structures visible through cuticle; internal genitalia as in Figs 124, 129, 130, with pair of highly distinctive three-layered telescopic tubes.

\section{Natural history}

All specimens were found in one small section of forest along a small river. No further specimens were found in two days of intensive search. They built barely visible webs on the undersides of live leaves, and often shared webs with large numbers of Diptera (Cecidomyiidae, in ZFMK).

\section{Distribution}

Known from type locality in northern Borneo (Sarawak) only (Fig. 1).
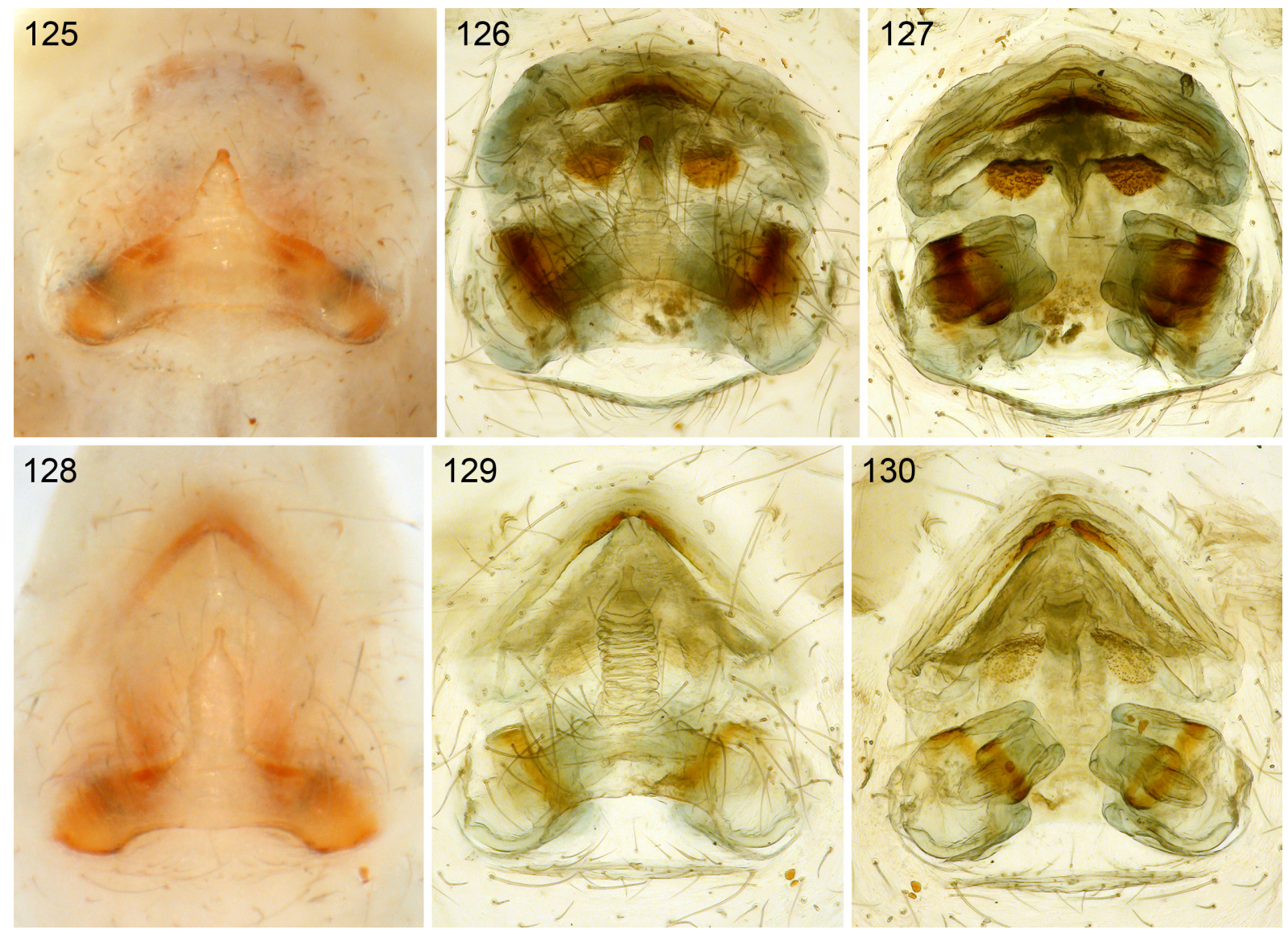

Figs 125-130. Epigyna, ventral views, and cleared female genitalia, ventral and dorsal views. 125127. Pholcus tambunan Huber sp. nov. (ZFMK, Ar 15712). 128-130. P. bario Huber sp. nov. (ZFMK, Ar 15718). 
Pholcus domingo species group

\section{Diagnosis}

The two species included in this group are medium-sized, long-legged spiders (body length $\sim 4.5$, male leg 1 length: 35-40), distinguished from similar P. kerinci group by bipartite appendix (sclerotized retrolateral and whitish prolateral part; Figs 140, 150, 157), by shape of procursus (presence of dorsal process; absence of distal spine-like process; Figs 141, 158), and by dorsal trichobothrium of male palpal tibia in 'usual' position (i.e., at $\sim 45 \%$ of tibia length, versus $55-60 \%$ in $P$. kerinci group); from other species groups in Pholcus by combination of the following characters: elongate abdomen angular dorso-posteriorly (Fig. 139); eight eyes; male chelicerae almost unmodified (indistinct lateral humps proximally; Fig. 142); male genital bulb without uncus; epigynum weakly sclerotized, with numerous transversal folds (Figs 143, 156, 159).

\section{Description}

See individual descriptions of the two very similar species below.

\section{Composition}

Only the two species described below.

\section{Natural history}

Both species were found on the undersides of live leaves where they built very fine webs tightly attached to the leaf surface. For further information, see description of $P$. domingo Huber sp. nov. below.

\section{Distribution}

The $P$. domingo group is restricted to Mindanao (Fig. 1).

Pholcus domingo Huber sp. nov. urn:1sid:zoobank.org:act:DE8B7640-CD1E-469F-B43B-BF319FEB156E

Figs 131-137, 140-156, 161-163

\section{Diagnosis}

Distinguished from most similar known relative (P. matutum Huber sp. nov.) by morphology of male palps (Figs 140-141; longer procursus with shorter dorsal process; appendix with long rod-shaped main branch); females of these two species are difficult to separate (internal genitalia relatively shorter in P. matutum Huber sp. nov.; compare Figs 144 and 160).

\section{Etymology}

The species name is derived from the type locality; noun in apposition.

\section{Material examined}

\section{Holotype}

PHILIPPINES: đa, ZFMK (Ar 15719), Mindanao, Bukidnon Prov., Santo Domingo (7.782 ${ }^{\circ}$, $\left.125.397^{\circ} \mathrm{E}\right), 560 \mathrm{~m}$ a.s.1., forest remnant along brook, on leaf, 8-9 Feb. 2014 (B.A. Huber, E. Mondejar).

\section{Other material}

PHILIPPINES: $9 \hat{\delta} \hat{\delta}, 9$ 우, 2 juvs, ZFMK (Ar 15720-21), and $1 \hat{\jmath}, 1$, , MSU-IIT, same data as holotype; $2 \widehat{\jmath} \hat{\jmath}, 5$ 우, in absolute ethanol, same data, ZFMK (Phi 287); 1 + with parasitized egg-sac, in absolute ethanol, ZFMK (Phi 286), same data; 5 đิ $\widehat{0}, 4$ 우, 1 juv., ZFMK (Ar 15722), near Santo 
Domingo, Malangob $\left(7.789^{\circ} \mathrm{N}, 125.384^{\circ} \mathrm{E}\right), 570 \mathrm{~m}$ a.s.l., forest along brook, on leaves, 9 Feb. 2014 (B.A. Huber, E. Mondejar).

\section{Assigned tentatively}

PHILIPPINES, Mindanao: 1 đ, 1 q, ZFMK (Ar 15723), Bukidnon Prov., CEDAR (Center for Ecological Development and Recreation) $\left(8.251^{\circ} \mathrm{N}, 125.034^{\circ} \mathrm{E}\right), 760 \mathrm{~m}$ a.s.l., forest along river, on
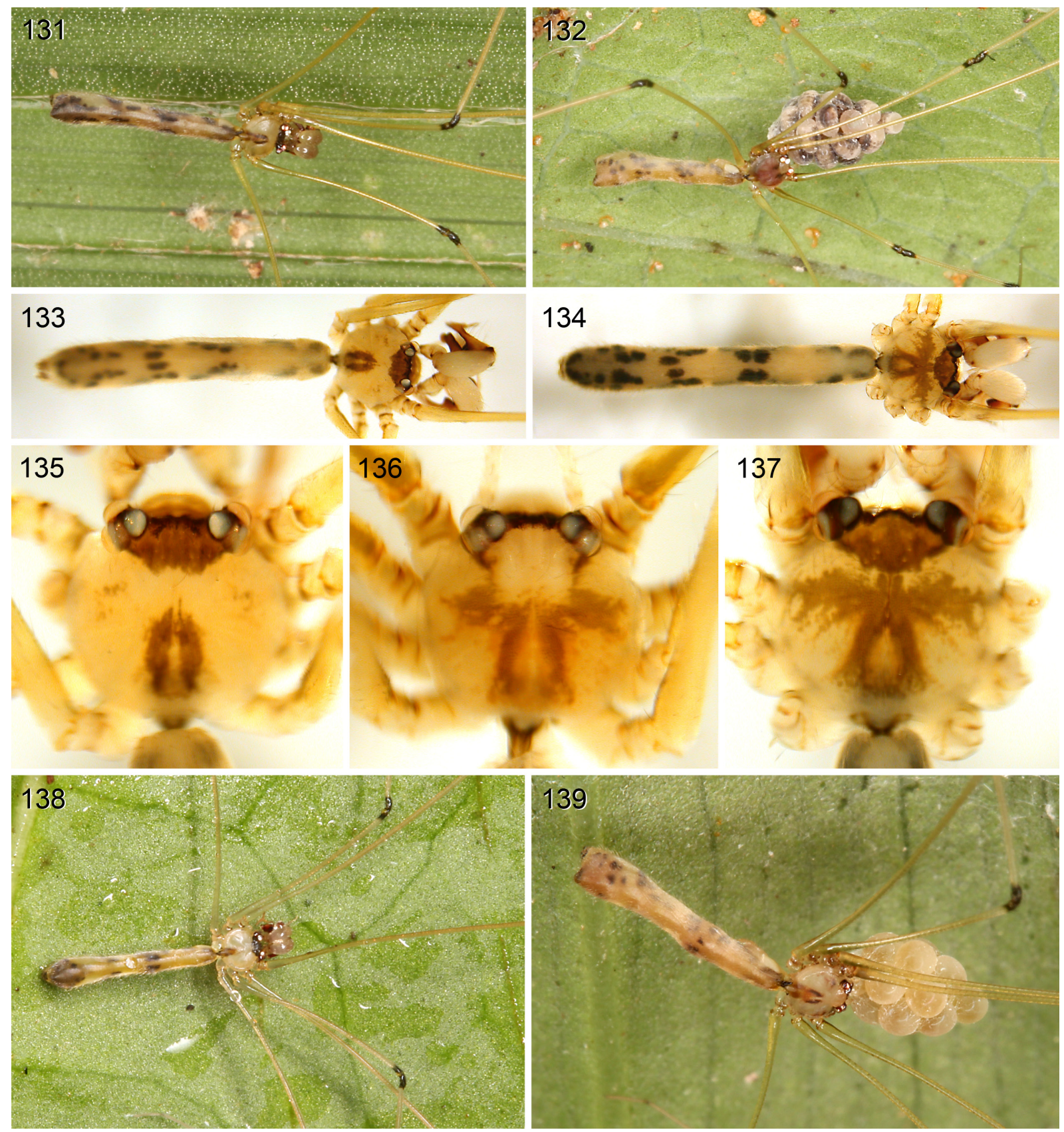

Figs 131-139. Live specimens and dorsal color patterns, Pholcus domingo group. 131-137. Pholcus domingo Huber sp. nov., $\sigma^{\uparrow}$ and $q$ with parasitized egg-sac from Santo Domingo (131-132), habitus of $\widehat{\partial} \widehat{\partial}$ from Santo Domingo (133) and Mt. Mupo (134), and carapace dorsal views, $\hat{O}$ and $q$ from Santo Domingo (135-136) and $\delta^{\Uparrow}$ from Mt. Mupo (137). 138-139. P. matutum Huber sp. nov., Mt. Matutum, $\widehat{\partial}$ and $q$ with egg-sac. 
leaves, 16 Feb. 2014 (B.A. Huber, E. Mondejar); 1 \&, 3 juvs, in absolute ethanol, ZFMK (Phi 249), same data; $2 \hat{\jmath} \hat{\partial}, 3$ 우, 2 juvs, ZFMK (Ar 15724), and $2 \hat{\partial} \hat{o}$, MSU-IIT, same locality, 15 Nov. 2014 (E.P. Mondejar); 1 đ̃, 3 우, ZFMK (Ar 15725), Davao del Sur Prov., Malagos Watershed $\left(7.184^{\circ} \mathrm{N}\right.$, $\left.125.415^{\circ} \mathrm{E}\right), 390 \mathrm{~m}$ a.s.1., forest along river, on leaves, $14 \mathrm{Feb} .2014$ (B.A. Huber, E. Mondejar); 1 ○, 1 \%,
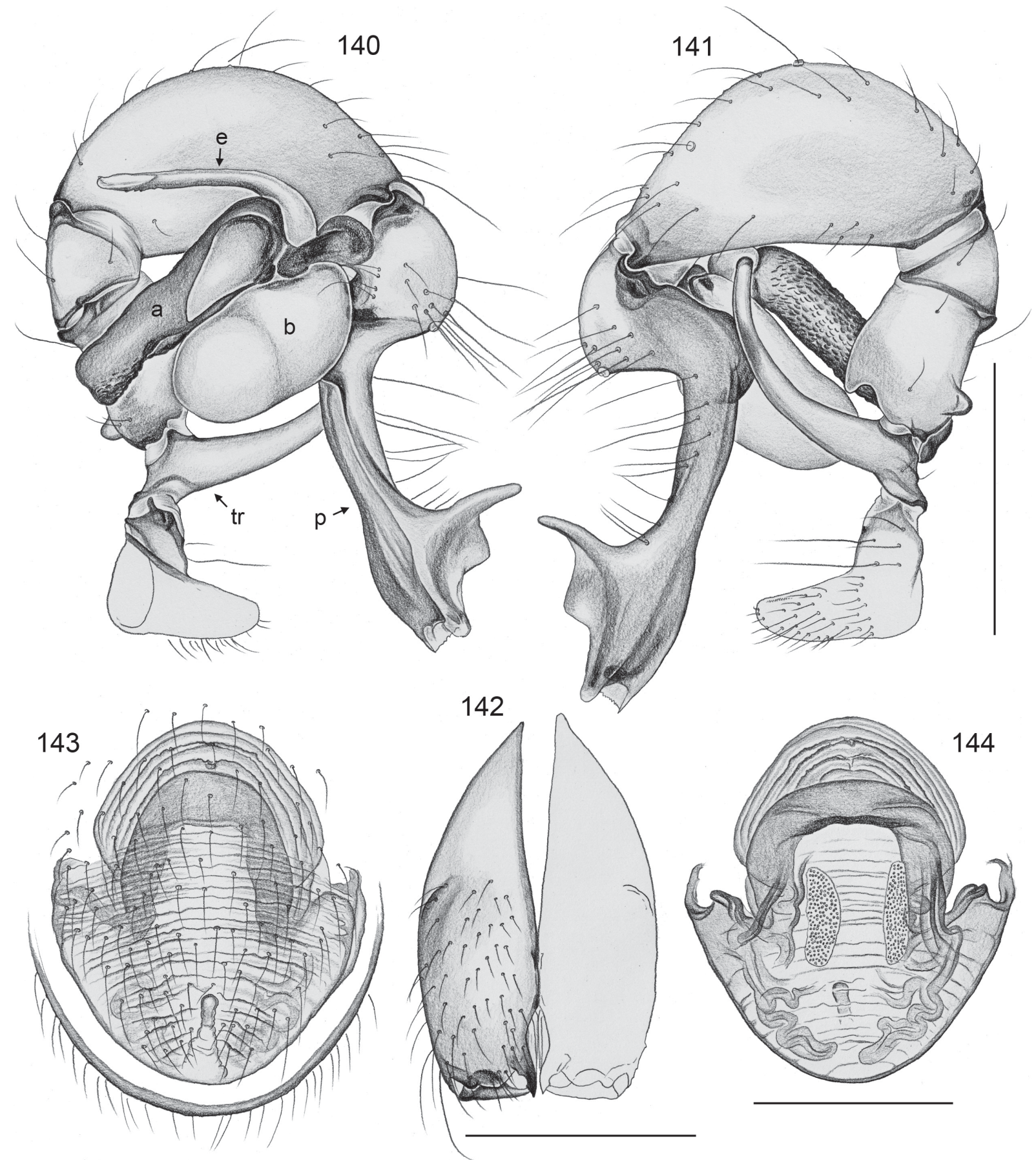

Figs 140-144. Pholcus domingo Huber sp. nov. (ZFMK, Ar 15720-21). 140-141. Left male palp, prolateral and retrolateral views. 142. Male chelicerae, frontal view. 143-144. Cleared female genitalia, ventral and dorsal views. Scale bars: $140-141=0.5 \mathrm{~mm} ; 142-144=0.3 \mathrm{~mm}$. 
1 juv. (identity of juvenile uncertain), in absolute ethanol, ZFMK (Phi 260), same data; 1 \&, ZFMK (Ar 15726), Davao City, Marilog Distr., Epol Falls, 'site 1' (7.456º N, 125.237E), 1100 m a.s.1., 1 Dec. 2014 (M.A. Responte); 1 ${ }^{\lambda}$, ZFMK (Ar 15727), Lanao del Sur Prov., Marawi City, Mt. Mupo $\left(8.018^{\circ} \mathrm{N}\right.$,

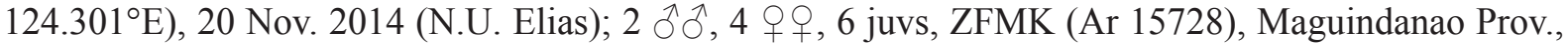
Dimapatoy Watershed $\left(7.141^{\circ} \mathrm{N}, 124.202^{\circ} \mathrm{E}\right), 17$ Dec. 2014 (N.U. Elias).

\section{Description}

Male (holotype)

MeAsurements. Total body length 4.5, carapace width 0.9. Leg 1: $35.9(8.6+0.4+8.7+16.6+1.6)$, tibia 2: 5.4, tibia 3: 3.0, tibia 4: 4.5; tibia $1 \mathrm{~L} / \mathrm{d}$ : 107 . Distance PME-PME $250 \mu \mathrm{m}$, diameter PME $100 \times 120 \mu \mathrm{m}$, distance PME-ALE $\sim 30 \mu \mathrm{m}$; distance AME-AME $40 \mu \mathrm{m}$, diameter AME $15 \mu \mathrm{m}$.

COLOR. Carapace pale ochre with pair of dark marks near median line posteriorly, ocular area also dark, clypeus pale ochre; sternum grey-brown, with light mark behind labium; legs ochre-yellow with dark brown patellae and tibia-metatarsus joints; abdomen pale ochre-gray with black marks dorsally and laterally, monochromous ventrally except pair of small brown spots in book-lung area.

Body. Habitus as in Figs 131 and 133; ocular area slightly raised, each triad on additional short hump (Fig. 148); carapace without median furrow; clypeus unmodified; sternum wider than long $(0.60 / 0.50)$, unmodified. Gonopore with four epiandrous spigots (Fig. 152).

Chelicerae. As in Fig. 142, barely modified, with indistinct lateral humps proximally, without distal modification, without modified hairs; without stridulatory ridges.
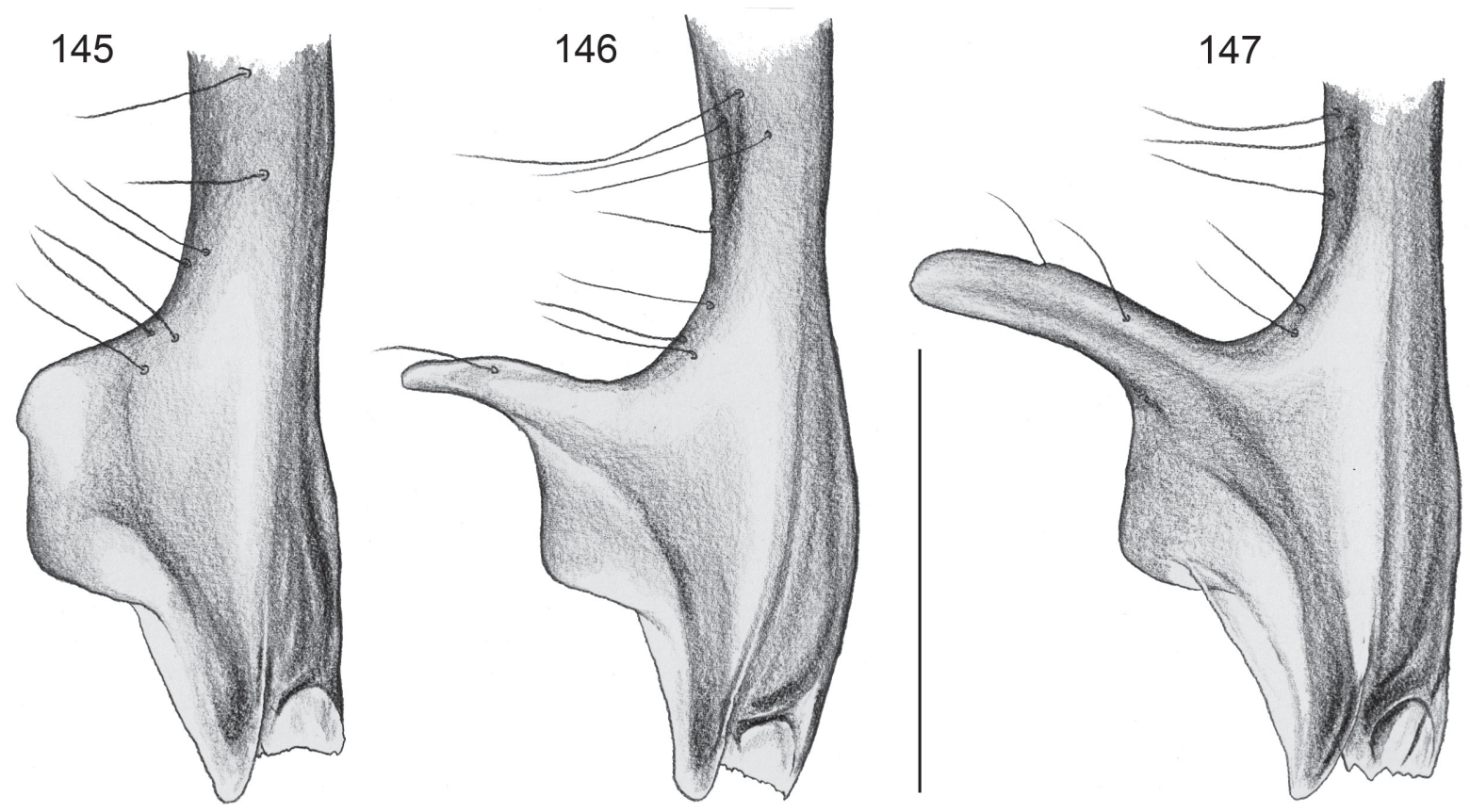

Figs 145-147. Pholcus domingo Huber sp. nov., tips of left procursi, retrolateral views. 145. Dimapatoy (ZFMK, Ar 15728). 146. Santo Domingo (type locality) (ZFMK, Ar 15720). 147. Mt. Mupo (ZFMK, Ar 15727). Scale bar $=0.3 \mathrm{~mm}$. 

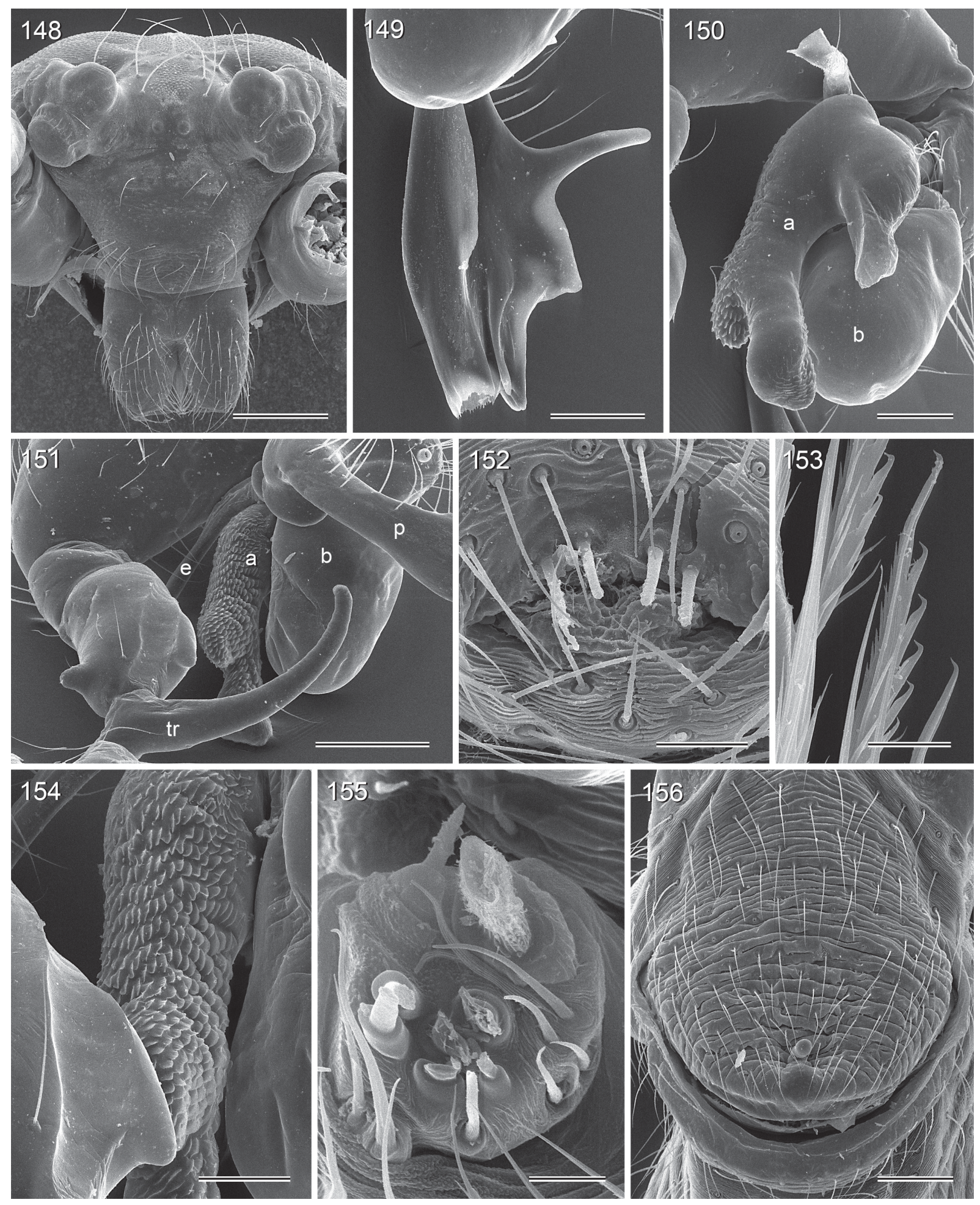

Figs 148-156. Pholcus domingo Huber sp. nov., SEM micrographs (ZFMK, Ar 15720-21). 148. Male prosoma, frontal view. 149. Tip of left procursus, prolateral view. 150. Left bulb and appendix, prolaterodistal view. 151. Right male palp, retrolatero-distal view. 152. Male gonopore. 153. Comb-hairs on male tarsus 4. 154. Right appendix, retrolateral view. 155. Female ALS. 156. Epigynum, ventral view. Scale bars: $148,151=200 \mu \mathrm{m} ; 149-150,156=100 \mu \mathrm{m} ; 152=30 \mu \mathrm{m} ; 153,155=10 \mu \mathrm{m} ; 154=60 \mu \mathrm{m}$. 
PALPS. As in Figs 140-141; coxa unmodified; trochanter with very long curved ventral apophysis; femur with ventral and retrolatero-dorsal processes; tibia very large (relative to femur); procursus rather simple, with strong ventral 'knee' and distinctive dorsal process distally (Fig. 149); bulb with long semitransparent embolus and large sclerotized process (putative appendix) densely covered with scales on retrolateral surface (Figs. 151, 154), with lighter prolateral branch proximally (Fig. 150).

LEGS. Without spines and curved hairs; few vertical hairs; retrolateral trichobothrium on tibia 1 at 3\%; prolateral trichobothrium absent on tibia 1, present on other tibiae; tarsus 1 with $>20$ pseudosegments, only distally a few fairly distinct. Tarsus 4 comb-hairs as in Fig. 153.

Male (variation)

Dorsal process of procursus varies considerably among localities: in comparison to males from type locality (Santo Domingo; Fig. 146), it is slightly more slender in male from Malagos; considerably stronger and longer in male from Mt. Mupo (Fig. 147; males from CEDAR intermediate between males from type locality and male from Mt. Mupo); almost absent in males from Dimapatoy (Fig. 145). Male from Mt. Mupo also with slightly different appendix (distal part of sclerotized main branch slightly longer). Males from Dimapatoy with slightly shorter trochanter apophysis. All specimens other than those from Santo Domingo are therefore assigned tentatively to this species. Sternum in most males examined either monochromous whitish or whitish with a few darker marks posteriorly; only one male from Malangob, male from Malagos, and male from Mt. Mupo like holotype; male from Mt. Mupo with more complex carapace pattern (Fig. 137; similar to females from other localities). Tibia 1 in 15 other males: 7.4-9.0 (mean 8.2).

\section{Female}

In general similar to male but sternum always dark brown and carapace pattern different: in most females posterior half with light brown to orange pattern (Fig. 136), one female from Dimapatoy with pattern like male holotype. Eye triads slightly closer together than in males (PME-PME distance: $200 \mu \mathrm{m}$ ). Tibia 1 in 19 females: 6.0-7.0 (mean 6.6). Epigynum very simple, weakly sclerotized (Fig. 161), with transverse ridges and finger-shaped posterior 'knob' (Figs 143, 156); internal genitalia as in Figs 144, 162, 163. ALS with one large widened, one pointed, and six smaller cylindrically-shaped spigots (Fig. 155). The single female specimen from Epol Falls is assigned tentatively because no males are known from this locality.

\section{Natural history}

At Santo Domingo and CEDAR, the spiders were found in very fine, barely visible webs tightly attached to the leaf surface of live leaves about 50-200 cm above the ground. The same kinds of leaves were also occupied by two species of Calapnita, and sometimes a Pholcus and a Calapnita were seen sharing a leaf. When disturbed, the Pholcus just remained still, with their bodies pressed against the leaf; when disturbed with more insistence, they ran away on the leaf or even let themselves down on a silk line. In the egg-sac of one female from the type locality, most eggs were parasitized by a parasitic wasp (Fig. 132).

\section{Distribution}

Known from several localities in Mindanao (Fig. 1; but note that specimens from most localities are assigned tentatively). 


\section{Pholcus matutum Huber sp. nov. urn:Isid:zoobank.org:act:CCCB3C54-30E8-4792-A4AC-F8A3A80DF703}

Figs 138-139, 157-160, 164-166

\section{Diagnosis}

Distinguished from most similar known relative ( $P$. domingo Huber sp. nov.) by morphology of male palps (Figs 157-158; shorter procursus with longer dorsal process; shorter and more pointed appendix); females of these two species are difficult to separate (internal genitalia relatively longer in $P$. domingo Huber sp. nov.; compare Figs 144 and 160).

\section{Etymology}

The species name is derived from the type locality; noun in apposition.

\section{Material examined}

\section{Holotype}

PHILIPPINES: Ô, ZFMK (Ar 15729), Mindanao, Mt. Matutum, Kawit Forest, 'site 1' $\left(6.338^{\circ} \mathrm{N}\right.$, $\left.125.104^{\circ} \mathrm{E}\right), 950 \mathrm{~m}$ a.s.l., along brook, on leaf, 13 Feb. 2014 (B.A. Huber, E. Mondejar).

\section{Other material}

PHILIPPINES: $4 \hat{\jmath} \hat{\partial}, 4$ q $\propto, 1$ juv., ZFMK (Ar 15730-31), and $1 \hat{\partial}, 1$ $\uparrow$, MSU-IIT, same data as holotype; 2 우, 3 juvs, in absolute ethanol, in ZFMK (Phi 269), same data; 1 q, RMNH, Mindanao, Davao, Mt. Apo Nature Reserve [ 7.03 ${ }^{\circ} \mathrm{N}, 125.40^{\circ} \mathrm{E}$ ?], $800 \mathrm{~m}$ a.s.1., on wild coffee leaf in secondary forest, 26 Apr. 1982 [R. Deeleman].

\section{Description}

\section{Male (holotype)}

Measurements. Total body length 4.4, carapace width 0.9. Leg 1: $36.9(8.8+0.4+8.8+17.3+1.6)$, tibia 2: 5.4, tibia 3: 3.2, tibia 4: 4.6; tibia $1 \mathrm{~L} / \mathrm{d}$ : 108. Distance PME-PME $260 \mu \mathrm{m}$, diameter PME $100 \times 120 \mu \mathrm{m}$, distance PME-ALE $\sim 30 \mu \mathrm{m}$; distance AME-AME $50 \mu \mathrm{m}$, diameter AME $15 \mu \mathrm{m}$.

CoLor. Carapace pale ochre, without dark pattern (only small internal medio-posterior structure visible through cuticle), ocular area also dark, clypeus pale ochre, only proximally darker; sternum whitish; legs ochre-yellow with dark brown patellae and tibia-metatarsus joints; abdomen pale ochre-gray with black marks dorsally and laterally, monochromous ventrally except pair of small brown spots in book-lung area.

BoDy. Habitus as in Fig. 138; ocular area slightly raised, each triad on additional short hump; carapace without median furrow; clypeus unmodified; sternum wider than long $(0.60 / 0.50)$, unmodified.

Chelicerae. As in P. domingo Huber sp. nov. (cf. Fig. 142), barely modified, with indistinct lateral humps proximally.

PALPS. As in Figs 157-158; coxa unmodified; trochanter with very long curved ventral apophysis; femur with ventral and retrolatero-dorsal processes (slightly different shapes than in $P$. domingo Huber sp. nov.); tibia very large (relative to femur); procursus rather simple, with strong ventral 'knee' and distinctive long dorsal process distally; bulb with long semitransparent embolus and large sclerotized process (putative appendix) densely covered with scales on retrolateral surface, with lighter prolateral branch proximally (appendix with more pointed tip than in $P$. domingo Huber sp. nov.; prolateral branch with more rounded tip). 
LEGS. Without spines and curved hairs; few vertical hairs; retrolateral trichobothrium on tibia 1 at $3 \%$; prolateral trichobothrium absent on tibia 1, present on other tibiae; tarsus 1 with $>20$ pseudosegments, only distally a few fairly distinct.

Male (variation)

Some males with pair of small darker marks posteriorly on carapace (similar to $P$. domingo Huber sp. nov.). Tibia 1 in 5 other males: 8.3-9.3 (mean 8.7).

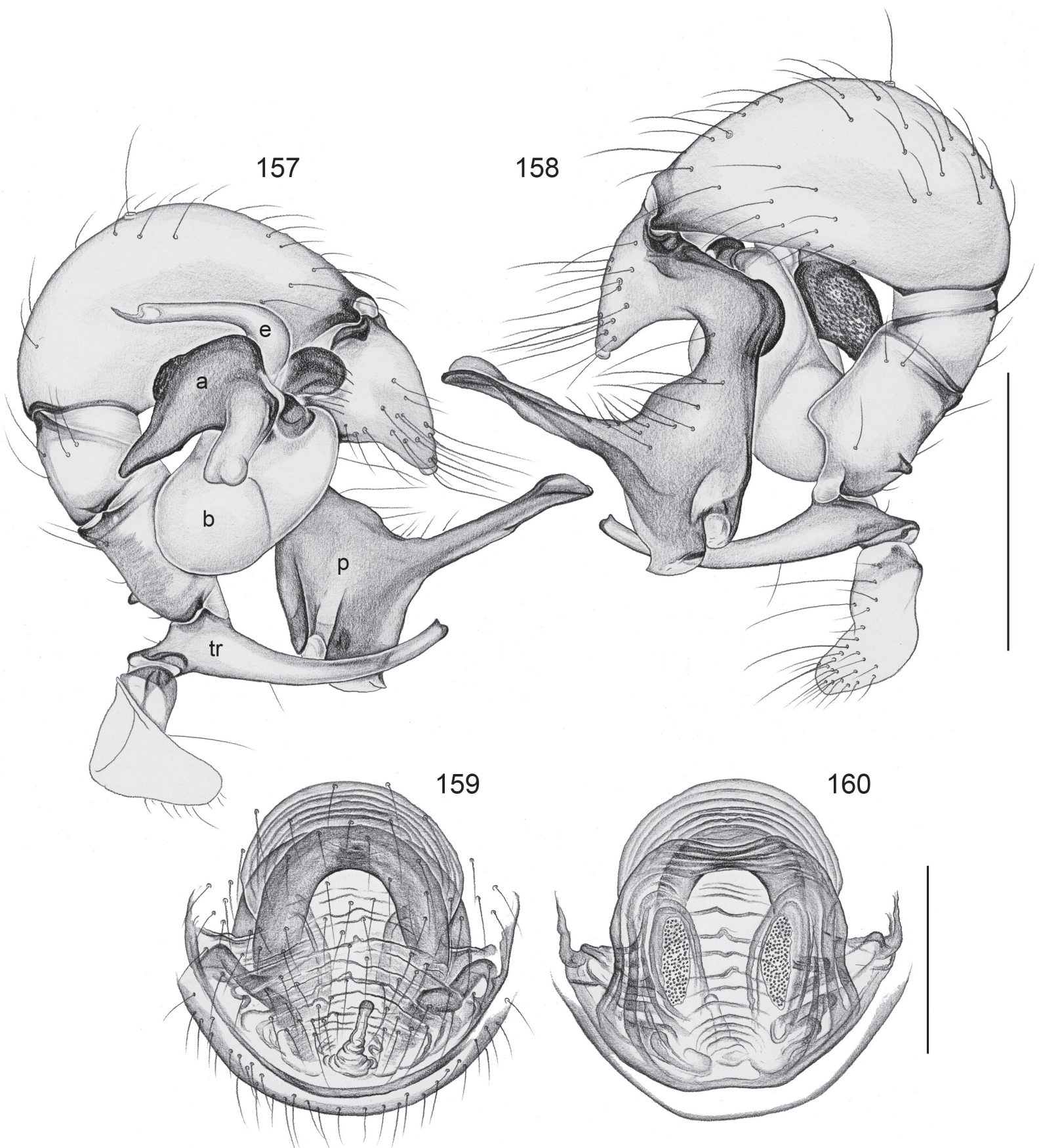

Figs 157-160. Pholcus matutum Huber sp. nov. (ZFMK, Ar 15730-31). 157-158. Left male palp, prolateral and retrolateral views. 159-160. Cleared female genitalia, ventral and dorsal views. Scale bars: $157-158=0.5 \mathrm{~mm} ; 159-160=0.3 \mathrm{~mm}$. 


\section{Female}

In general similar to male (Fig. 139), carapace pattern different: most females with two pairs of light brown to orange marks, one pair near median line posteriorly, one pair laterally; one female with same carapace pattern as $P$. domingo Huber sp. nov. (posterior half of carapace largely covered by light brown to orange pattern). Eye triads slightly closer together than in males (PME-PME distance: $230 \mu \mathrm{m}$ ). Tibia 1 in 4 females: 6.6, 6.9, 6.9, 7.2. Sternum whitish as is males (not brown as in P. domingo Huber sp. nov. females). Epigynum very simple, weakly sclerotized (Fig. 164), with transverse ridges and finger-shaped posterior 'knob' (Fig. 159); internal genitalia as in Figs 160, 165, 166.

\section{Natural history}

The spiders were found in very fine, barely visible webs tightly attached to the leaf surface of live leaves.

\section{Distribution}

Known from two localities in southern Mindanao (Fig. 1). The single female specimen from Epol Falls assigned tentatively to $P$. domingo Huber sp. nov. might actually belong to this species.
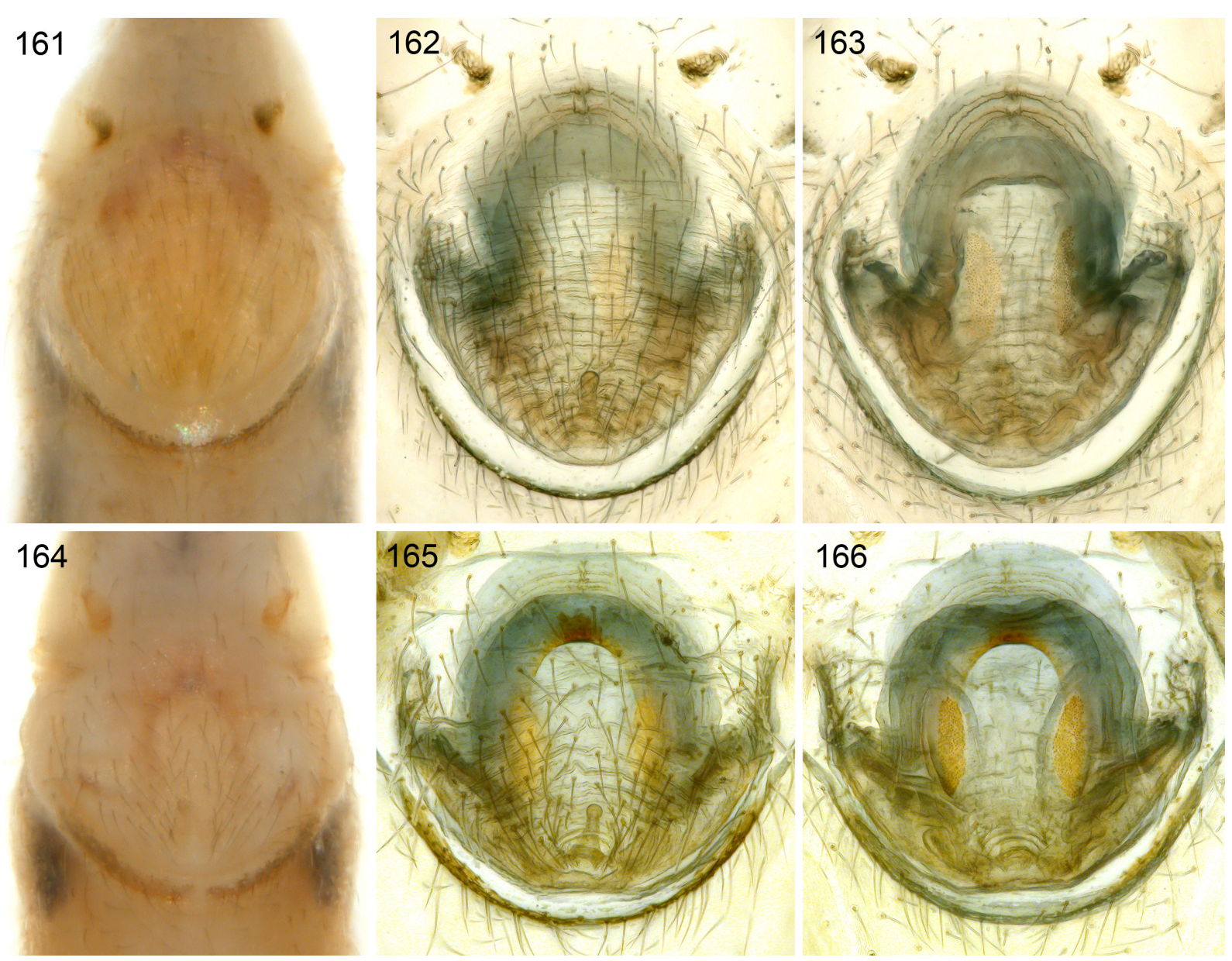

Figs 161-166. Epigyna, ventral views, and cleared female genitalia, ventral and dorsal views. 161-163. Pholcus domingo Huber sp. nov. (ZFMK, Ar 15721). 164-166. P. matutum Huber sp. nov. (ZFMK, Ar 15731). 


\section{Discussion}

None of the species described above is a 'typical' Pholcus, i.e., none of them belongs to what has been described as the "core group" of Pholcus (Huber 2011). Most representatives of this core group are characterized by the combination of two characters: a heavily sclerotized epigynal plate, and male chelicerae with proximal frontal apophyses. All species described above have very weakly sclerotized epigyna, and they lack proximal frontal apophyses on the male chelicerae (the apophyses in representatives of the $P$. ethagala group are considered homologues of the proximal lateral apophyses, a synapomorphy of Pholcinae; Huber 2011). This requires some justification for why we assign these species to Pholcus.

A first cladistic analysis of Pholcus (Huber 2011) has brought some structure into this large taxon (at that time 254 species; now almost 350 species), and it provided strong support for a group of genera close to Pholcus (the Pholcus group of ten genera). At the same time, it also highlighted some fundamental problems with Pholcus and its closest relatives. It suggested that Pholcus is a paraphyletic group and that at least some of the closely related genera like Panjange, Leptopholcus, Micropholcus, Micromerys, Calapnita, and Uthina Simon, 1893 may in fact be nested within Pholcus, more closely related to some 'basal' groups of Pholcus than to the core group. Taxonomic consequences (synonymization of existing genera and/or creation of new genera) were not implemented because the cladistic analysis seemed too preliminary to justify such formal decisions. The same reasoning lies behind our decision to place the new species in Pholcus, especially the two new species groups (the Pholcus ethagala group was already described in Huber 2011): these new taxa do clearly not belong to any of the nine genera closely related to Pholcus, and creating new genera for them might unnecessarily complicate future taxonomic decisions without adding to our current understanding of relationships. At some point a split of Pholcus will probably be necessary, but in our view this should be based on a large phylogenetic analysis, ideally including molecular data, all species groups of Pholcus, and a large sample of the nine closely related genera. Such an analysis is currently in progress (A. Valdez-Mondragón, B.A. Huber \& D. Dimitrov, unpublished data).

Interestingly, the taxonomic problem with Pholcus is largely an Indomalayan problem, and it seems to be closely related to evolutionary shifts of microhabitat. All Afrotropical species groups, the single Nearctic species group, and all Palaearctic species groups of Pholcus are quite unambiguous representatives of the core group of Pholcus (Huber 2011). Within this core group, the large majority of species occupy large sheltered spaces among rocks, logs, buttresses, etc.; very few species occupy the leaf litter and ground substrate (e.g., P. kribi Huber, 2011 in Cameroon; some members of the P. opilionoides group in North Africa, Huber 2011) or live leaves (e.g., the P. taarab group in East Africa and the P. debilis group in Central Africa; Huber 2011). Even these ecologically exceptional species and species groups are unambiguous representatives of the core group of Pholcus.

By contrast, the nine species groups assigned tentatively to Pholcus are all Indomalayan: $P$. andulau group, $P$. buatong group, $P$. domingo group, $P$. ethagala group, $P$. halabala group, $P$. kerinci group, P. krabi group, P. minang group, P. tambunan group (Huber 2011; Huber et al. 2016; herein). Most of the species included in these species groups occupy either the leaf litter of live leaves; exceptions are a few cave- and rock-dwelling species such as P. hurau Huber, 2011; P. diopsis Simon, 1901; P. kuhapimuk Huber, 2016; P. khaolek Huber, 2016; P. sudhami Huber, 2011; and P. buatong Huber, 2016 (Huber 2011; Huber et al. 2016). Three of the problematic genera possibly nested within Pholcus are also leaf-dwelling and Indomalayan (partly reaching Australia): Calapnita, Panjange, and Micromerys. A possible explanation to be tested in future phylogenetic analyses is that Pholcus in Southeast Asia has a longer history of leaf-dwelling than in tropical Africa, resulting in more conspicuous deviations from the 'typical' morphology of Pholcus, which in turn obscured relationships and prompted researchers to 
create possibly unjustified new genera. Future large scale analyses of Pholcus should thus continue to focus on Indomalayan taxa.

\section{Acknowledgements}

We thank David Court, Venus Saksongmuang, Mustakiza Muslimin, Eddie P. Mondejar, and Samuel B. Huber for accompanying us in the field; Mae A. Responte, Eddie P. Mondejar, and Noraya U. Elias for contributing specimens from their own research; our Thai drivers Usman Hayee-Aarwae, Jeerabute Suwannatut, and Preesha Petsout and our Philippine driver Vicente Bulongon for bringing us safely to all requested places; Björn Rulik for identifying the flies found in pholcid webs; Sara Bumrungsri for supporting our permit requests in Thailand; Noraishah Mydin Abdul Aziz for facilitating field work in Malaysia; the Sarawak Museum Department for assistance in field logistics; the National Research Council of Thailand (NRCT), the Singapore National Parks Board (Permit No. NP/RP15-003a), the Sarawak Forest Department (Permit No. NCCD.907.4.4 JLD.10-211, Park Permit No. 174/2014) and the Philippine Department of Environment and Natural Resources (DENR) CARAGA, DENR Region $\mathrm{X}$, and DENR Region XI, for issuing permits; and the German Research Foundation for financial support (DFG Project HU 980/11-1).

\section{References}

Brown B.V. 1993. A further chemical alternative to critical-point-drying for preparing small (or large) flies. Fly Times 11: 10.

Dimitrov D., Astrin J.J. \& Huber B.A. 2013. Pholcid spider molecular systematics revisited, with new insights into the biogeography and the evolution of the group. Cladistics 29: 132-146. http://dx.doi. org/10.1111/j.1096-0031.2012.00419.x

Huber B.A. 2005. High species diversity, male-female coevolution, and metaphyly in Southeast Asian pholcid spiders: the case of Belisana Thorell, 1898 (Araneae, Pholcidae). Zoologica 155: 1-126.

Huber B.A. 2011. Revision and cladistic analysis of Pholcus and closely related taxa (Araneae, Pholcidae). Bonner zoologische Monographien 58: 1-509.

Huber B.A. 2012. Revision and cladistic analysis of the Afrotropical endemic genus Smeringopus Simon, 1890 (Araneae: Pholcidae). Zootaxa 3461: 1-138.

Huber B.A. 2015. Small scale endemism in Brazil's Atlantic Forest: 14 new species of Mesabolivar (Araneae, Pholcidae), each known from a single locality. Zootaxa 3942: 1-60. http://dx.doi.org/10.11646/ zootaxa.3942.1.1

Huber B.A., Dimitrov D. 2014. Slow genital and genetic but rapid non-genital and ecological differentiation in a pair of spider species (Araneae, Pholcidae). Zoologischer Anzeiger 253: 394-403. http://dx.doi.org/10.1016/j.jcz.2014.04.001

Huber B.A., Fischer N. \& Astrin J.J. 2010. High level of endemism in Haiti's last remaining forests: a revision of Modisimus (Araneae: Pholcidae) on Hispaniola, using morphology and molecules. Zoological Journal of the Linnean Society 158: 244-299. http://dx.doi.org/10.1111/j.1096-3642.2009.00559.x

Huber B.A. \& Fleckenstein N. 2008. Comb-hairs on the fourth tarsi in pholcid spiders (Araneae, Pholcidae). Journal of Arachnology 36: 232-240. http://dx.doi.org/10.1636/CSh07-71.1

Huber B.A., Nuñeza O.M. \& Leh Moi Ung C. 2015. Revision, phylogeny, and microhabitat shifts in the Southeast Asian spider genus Aetana (Araneae, Pholcidae). European Journal of Taxonomy 162: 1-78. http://dx.doi.org/10.5852/ejt.2015.162 
Huber B.A., Petcharad B., Leh Moi Ung C., Koh J.K.H. \& Ghazali A.R.M. 2016. The Southeast Asian Pholcus halabala species group (Araneae, Pholcidae): new data from field observations and ultrastructure. European Journal of Taxonomy 190: 1-55. http://dx.doi.org/10.5852/ejt.2016.190

Huber B.A., Rheims C.A. \& Brescovit A.D. 2005. Two new species of litter-dwelling Metagonia spiders (Araneae, Pholcidae) document both rapid and slow genital evolution. Acta Zoologica (Stockholm) 86: 33-40. http://dx.doi.org/10.1111/j.0001-7272.2005.00184.x

Walckenaer C.A. 1805. Tableau des aranéides ou caractères essentiels des tribus, genres, familles et races que renferme le genre Aranea de Linné, avec la désignation des espèces comprises dans chacune de ces divisions. Imprimerie De Dentu, Paris.

Manuscript received: 25 January 2016

Manuscript accepted: 17 February 2016

Published on: 26 May 2016

Topic editor: Rudy Jocqué

Desk editor: Kristiaan Hoedemakers

Printed versions of all papers are also deposited in the libraries of the institutes that are members of the EJT consortium: Muséum national d'Histoire naturelle, Paris, France; Botanic Garden Meise, Belgium; Royal Museum for Central Africa, Tervuren, Belgium; Natural History Museum, London, United Kingdom; Royal Belgian Institute of Natural Sciences, Brussels, Belgium; Natural History Museum of Denmark, Copenhagen, Denmark. 